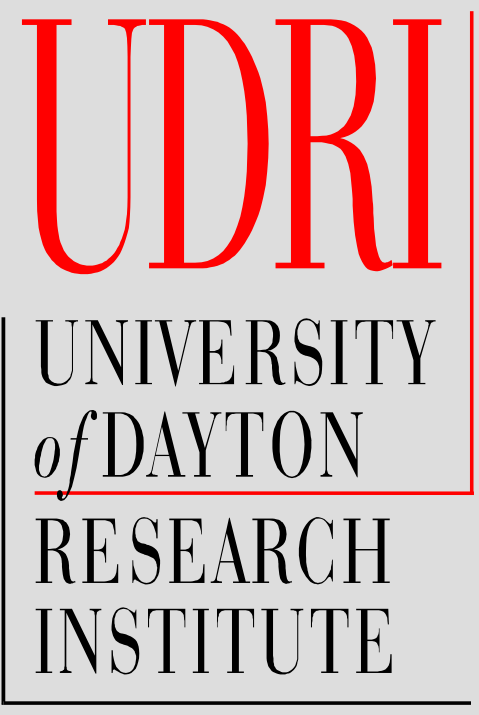

Report

ELEVATED

TEMPERATURE

SENSORS FOR ON-LINE

CRITICAL EQUIPMENT

HEALTH MONITORING

July 2006 


\title{
Elevated Temperature Sensors for On-Line Critical Equipment Health Monitoring
}

\author{
Final Report
}

July 2006

Contract No. DE-FG26-02NT41534

Prepared for:

U.S. Department of Energy

National Energy Technology Laboratory

Pittsburgh, PA 15236

Prepared by:

James Sebastian, P.E.

STRUCTURAL INTEGRITY DIVISION

300 College Park

Dayton, OH 45469-0120 
TITLE:

\section{ELEVATED TEMPERATURE SENSORS FOR ON-LINE CRITICAL EQUIPMENT HEALTH MONITORING}

REPORT TYPE: $\quad$ Final Report

REPORTING

PERIOD:

October 2002 - March 2006

PI:

James Sebastian

STUDENTS: $\quad$ Michael Frede, Matthew Pacyna

DATE REPORT

ISSUED:

July 2006

GRANT NO:

DE FG26-02NT41534

INSTITUTION: University of Dayton Research Institute Structural Integrity Division

300 College Park

Dayton, OH 45469-0120

(937) 229-4417

(937) 229-3712 (Fax)

sebastian@udri.udayton.edu

Technical Report\# UDR-TR-2006-00158 
This report was prepared as an account of work sponsored by an agency of the United States Government. Neither the United States Government nor any agency thereof, nor any of their employees, makes any warranty, express or implied, or assumes any legal liability or responsibility for the accuracy, completeness, or usefulness of any information, apparatus, product, or process disclosed, or represents that its use would not infringe privately owned rights. Reference herein to any specific commercial product, process, or service by trade name, trademark, manufacturer, or otherwise does not necessarily constitute or imply its endorsement, recommendation, or favoring by the United States Government or any agency thereof. The views and opinions of authors expressed herein do not necessarily state or reflect those of the United States Government or any agency thereof. 
The objective of the program was to improve high temperature piezoelectric aluminum nitride (AlN) sensor technology to make it useful for instrumentation and health monitoring of current and future electrical power generation equipment. Improvements were aimed primarily at extending the useful temperature range of the sensor from approximately $700^{\circ} \mathrm{C}$ to above $1000^{\circ} \mathrm{C}$, and investigating ultrasonic coupling to objects at these temperatures and tailoring high temperature coupling for use with the sensor. During the project, the chemical vapor deposition (CVD) AlN deposition process was successfully transferred from film production on tungsten carbide substrates to titanium alloy and silicon carbide (SiC) substrates. Film adhesion under thermal cycling was found to be poor, and additional substrate materials and surface preparations were evaluated. A new, porous SiC substrate improved the performance but not to the point of making the films useful for sensors. Near the end of the program, a new family of high temperature piezoelectric materials came to the attention of the program. Samples of langasite, the most promising member of this family, were obtained and experimental data showed promise for use up to the $1000^{\circ} \mathrm{C}$ target temperature. In parallel, research successfully determined that metal foil under moderate pressure provided a practical method of coupling ultrasound at high temperature. A conceptual sensor was designed based upon these methods and was tested in the laboratory. 
$\underline{\text { Section }}$

Page

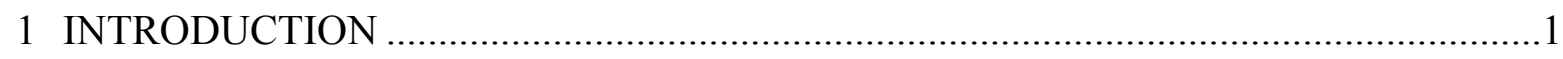

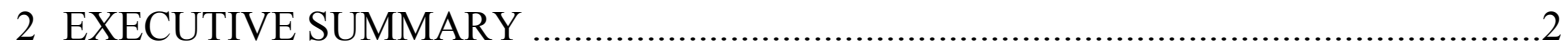

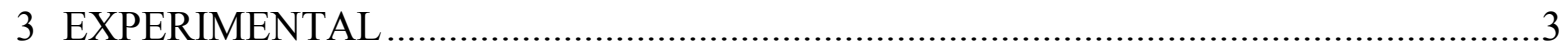

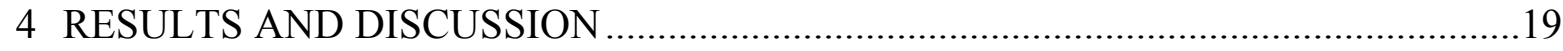

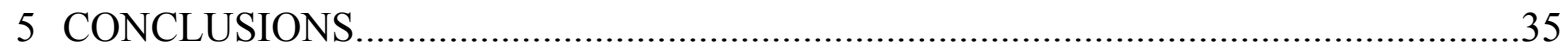




\section{SECTION 1 INTRODUCTION}

In order to use coal-fired electrical power generation equipment to its fullest potential, sensors are required which are capable of monitoring the "health" of critical system components. Such sensors can alert an operator to impending problems, if any, while reducing the need to shut down equipment for inspection. Benefits of health monitoring include reduced down time for inspection or unplanned outages. For equipment operating at high temperatures, this will also likely reduce thermal cycles and associated fatigue or wear. Equipment that can benefit from such health monitoring includes dynamic systems, such as turbine engines, as well as static systems such as gasifiers, process piping, or other chemical processing facilities.

Previous research conducted at the University of Dayton into the properties and behavior of Aluminum Nitride (AIN), a high temperature piezoelectric material, indicated that this material has a good potential for providing a basis for sensors that can be used for elevated temperature health monitoring, up to at least $1000^{\circ} \mathrm{C}\left(1800^{\circ} \mathrm{F}\right)$. The most straightforward implementation of such AlN sensors is as ultrasonic transducers, for example as a thickness monitor in a critical region of a metal or ceramic component exposed to corrosive or erosive conditions. Ultrasonic thickness gages are widely available commercially for room temperature measurements. Ultrasonic waves may additionally be used to monitor bonds, such as that between a metal and a ceramic, as found in thermal and environmental barrier coatings commonly found in power generation equipment.

The first year of this three-year effort focused on laying the groundwork for extending the sensor technology to the high temperature $\left(>1000^{\circ} \mathrm{C}\right)$ regime. The second year continued to extend this groundwork, including further investigations of high temperature coupling and substrate research for the AlN films. The third year brought coupling research to a successful conclusion. In addition, continued research into AIN film deposition confirmed the desirability of silicon carbide substrates, with porous $\mathrm{SiC}$ being the most promising. Deposition on the porous $\mathrm{SiC}$ was achieved, but as with the monolithic $\mathrm{SiC}$, good adhesion of the AlN films was not achieved.

In addition to the required poster at the University Coal Research annual review meeting, results from this research were presented at the Review of Quantitative Nondestructive Evaluation (QNDE), Brunswick, Maine, and the American Society for Nondestructive Testing (ASNT) annual meeting in Columbus, OH. Following up on leads generated at QNDE led to the discovery of a new high temperature piezoelectric material, langasite (LGS) which has much promise for overcoming the limitations of the AlN films and operating at ultrasonic frequencies below $15 \mathrm{MHz}$, the desirable range for most health monitoring and ultrasonic sensor applications. In addition, the langasite will not oxidize when used in air at high temperatures above the $700^{\circ} \mathrm{C}$ level where AlN requires protection. Samples of the LGS were obtained and test data recorded up to $980^{\circ} \mathrm{C}$, demonstrating its potential to cover the $700^{\circ}$ to $1000^{\circ}$ range. 


\section{SECTION 2 \\ EXECUTIVE SUMMARY}

The goal of this project was to develop sensors that can be used at elevated temperatures, up to $1000^{\circ} \mathrm{C}$, in power generation equipment. The primary target application for these sensors is equipment health monitoring. Historically, ultrasonic sensors have been used to evaluate properties of solid and fluid materials. Detected flaws may include cracks, voids, inclusions, porosity, or other discontinuities. Additionally, ultrasound is used industrially in flowmeters, proximity sensors, and for material thickness measurements.

Conventional ultrasonic transducers and instrumentation are temperature limited because the piezoelectric materials used in the transducer cannot operate above their Curie point or de-poling temperature. Operation above $100^{\circ} \mathrm{C}$ is considered "high temperature" with special requirements met by quartz or tourmaline transducers up to $\sim 450^{\circ} \mathrm{C}$, or complicated delay lines with complex cooling requirements (and usually) exposure times measured in seconds. Laser-based ultrasound and electromagnetic acoustic transducers (EMATs) are also used at high temperatures but are expensive or complicated. In addition, coupling the ultrasonic energy from the transducer into the test object becomes much more difficult above $100^{\circ} \mathrm{C}$.

The current project was directed toward developing ultrasonic transducers based on piezoelectric aluminum nitride (AIN) films to enable the use of ultrasound for material evaluation at temperatures exceeding $1000^{\circ} \mathrm{C}$. The majority of the project was spent trying to advance the AlN film deposition process to produce a film-substrate combination that could meet the $1000^{\circ} \mathrm{C}$ operating target temperature. This goal was not met after much effort due to the lack of AlN adhesion on a number of candidate substrates, with much of the work focusing on various forms of silicon carbide. However, an alternative approach using langasite crystals as the core of ultrasonic transducers was identified and preliminary testing on this material was performed. The originally planned transducer demonstration project was scaled down into an advanced test of a langasite-based transducer design, and it successfully operated to $980^{\circ} \mathrm{C}$, failing due to component oxidation with no degradation of the langasite crystal.

The results from the first year's literature survey on elevated temperature ultrasonic coupling pointed toward the use of molten glass or metal foil as a couplant material. These methods were further investigated and demonstrated experimentally in the second year. The use of molten glass was inconsistent; it worked but tended to react with materials in contact with it, as well as the air, and was unlikely to work as a long term solution. Metal foils showed much more promise as a robust couplant, beginning with aluminum foil at lower temperatures and extending on to gold at higher temperatures. Gold leaf was selected as the optimum solution for coupling in terms of both performance and cost. Transducers derived from this research have the potential to fill niche roles in health monitoring and other high temperature sensor needs. 


\section{SECTION 3 \\ EXPERIMENTAL}

\section{Piezoelectric AlN Film Deposition}

Most of the efforts in the first year of the program were directed toward chemical vapor deposition (CVD) of piezoelectric aluminum nitride films. The thick films required for this project were created through a CVD process based on the deposition process described in Canadian Patents \#2269581 and \#2219404. This process begins with heating the substrate to $\sim 700^{\circ} \mathrm{C}$ through induction heating in an inert environment in the CVD reactor. Argon, ammonia and aluminum bromide gases are flowed over the substrate, some of which react to form AlN on the surface of the substrate, at a deposition rate on the order of $0.01 \mathrm{~mm}$ per hour. Prior to deposition, the surface of the substrate is polished and cleaned with a solvent. The process is essentially the same for all substrates tried to date.

During deposition, AlN crystals nucleate on the surface, and the crystals with the desired orientation for piezoelectric use grow in the thickness direction. Occasionally the crystal structure will be disrupted, leaving a pinhole gap or similar defect in the film; previous work with the deposition process has reduced the occurrence of such defects. More commonly, similar defects begin to form after the film has begun to grow, resulting in low areas in the films. The occurrence of defects in this manner limits the overall film thickness, as more defects occur as the film grows. The surface is initially polished by hand on 400 grit $\mathrm{SiC}$ paper after deposition to eliminate high spots for the initial ultrasonic evaluation. Further polishing on 400 and 600 grit paper is required to maximize the ultrasonic signal, with additional lapping sometimes used. Figure 1 shows a polished AlN film deposited on tungsten carbide.

Pulsed laser deposition (PLD) was also used to create three AlN films in order to evaluate it as an alternative method. In this process, an Al target is irradiated with the fundamental output

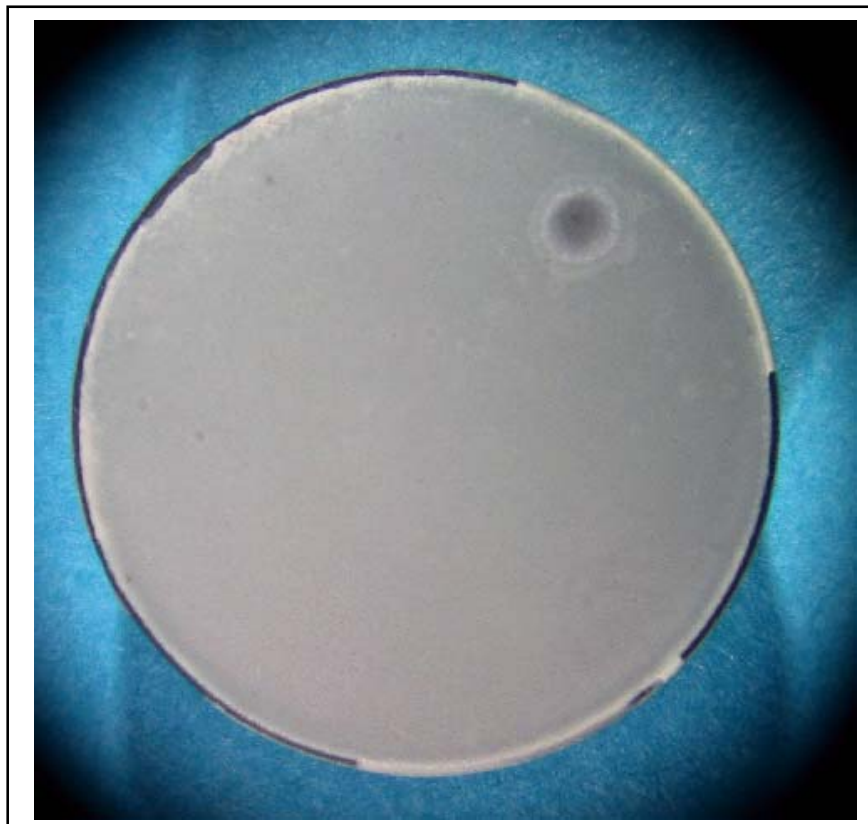

Figure 1. Polished AlN film on WC $(\lambda=1064 \mathrm{~nm})$ of a Q-switched Nd:Yag laser with a heated substrate placed within a few $\mathrm{mm}$ of the irradiated area. The ablation is performed in a background pressure of ammonia in a vacuum chamber, forming AlN on the heated substrate. Placing the substrate at such a close distance to the target allows most of the ejected material to strike the target. The laser can deliver up to 400 $\mathrm{mJ} /$ pulse of its fundamental radiation. An infrared pyrometer was used to determine the substrate temperature during deposition. The films deposited by PLD have not been further polished. Figure 2 shows an AlN film deposited on silicon carbide using the PLD method. 
In the second year, the same CVD process was used to attempt to transition the deposition onto silicon carbide $(\mathrm{SiC})$ substrates, rather than the cobalt-bonded tungsten carbide (WC) cermet that had historically been the substrate of choice. Two primary factors motivated this transition:

- The $\mathrm{SiC}$ is a better selection for use at temperatures above $700^{\circ} \mathrm{C}$. A coherent, protective silicon oxide forms at the

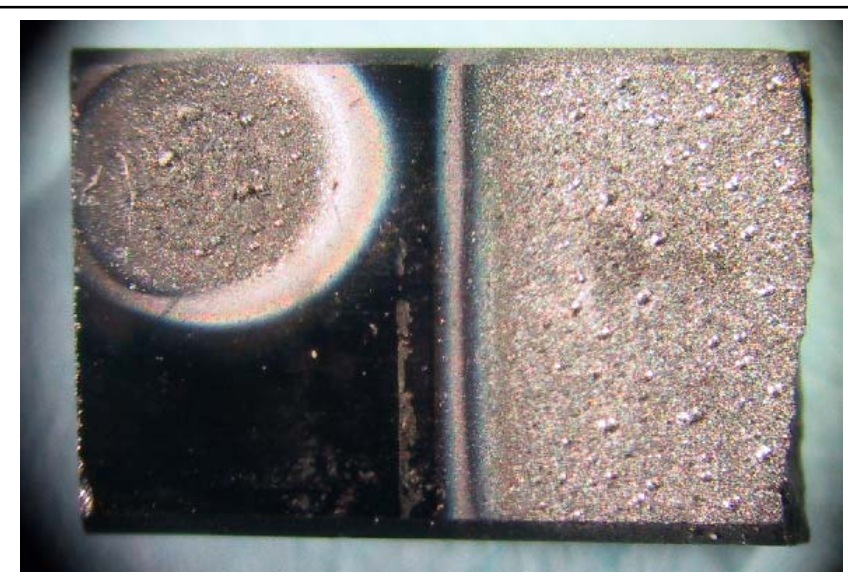

Figure 2. AlN film on SiC deposited by PLD. surface, which protects it against further oxidation to temperatures beyond $1000^{\circ} \mathrm{C}$. Use of $\mathrm{SiC}$ would ensure that the AlN sensor material's upper range is not limited by a substrate that oxidizes before it does. (AIN becomes sensitive to oxidation in the vicinity of $800^{\circ} \mathrm{C}$.)

- $\mathrm{SiC}$ is a much better acoustic impedance match for AlN. This is necessary to create a high bandwidth ultrasonic sensor capable of producing a pulse with minimal ringing. The difference between $\mathrm{WC}$ and $\mathrm{SiC}$ is shown in Figures 3 and 4. A high bandwidth signal provides better time resolution and sensor performance.

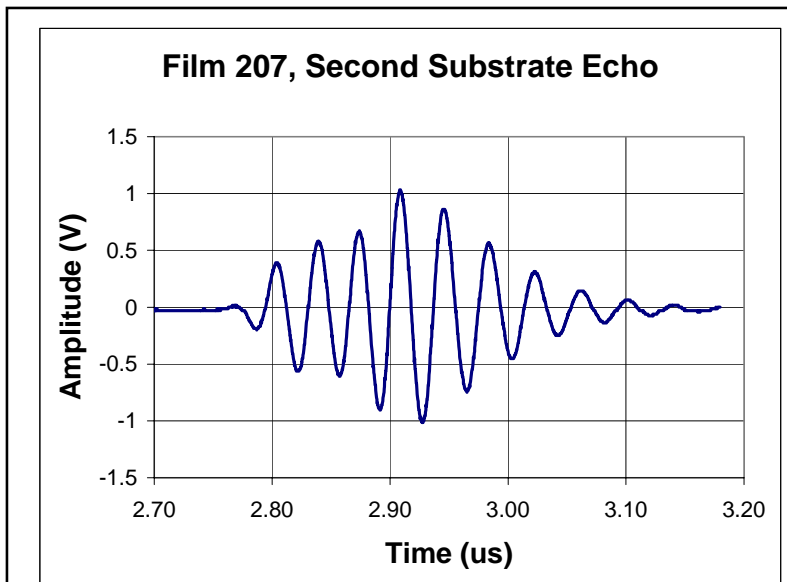

Figure 3. Narrowband ultrasonic signal with significant ringing produced by AIN film on WC substrate.

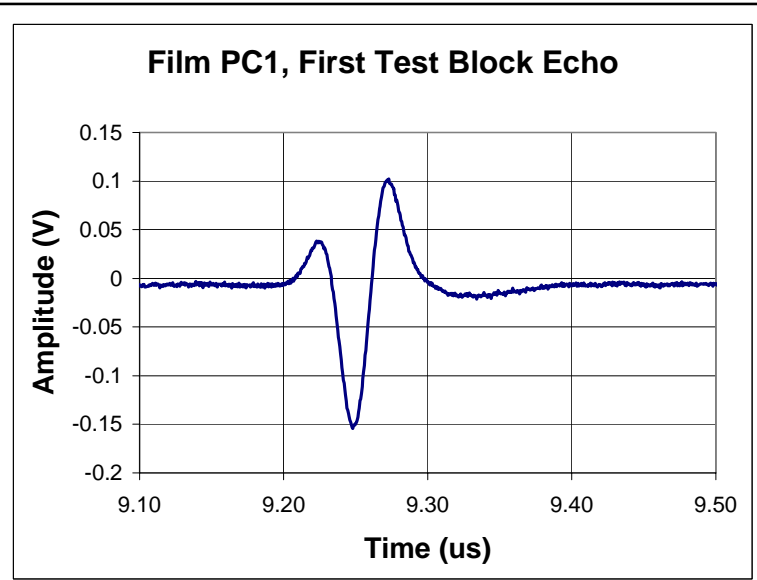

Figure 4. Wideband ultrasonic signal produced by AIN film on SiC substrate

$\mathrm{SiC}$ shapes are available in a number of different material sub-types, classified by composition and production method. Direct-sintered $\mathrm{SiC}$ is prepared by sintering $\mathrm{SiC}$ particles under heat and pressure to form a solid material. Reaction-bonded $\mathrm{SiC}$ is prepared from a blend of $\mathrm{SiC}$ and carbon powders, green pressed and infiltrated with molten silicon which reacts with the carbon, generally leaving some free silicon in the finished part. Solid $\mathrm{SiC}$ shapes may also be prepared by laying down successive layers with a chemical vapor deposition process, the most expensive method. Since the substrate is used as one of the electrodes to apply voltage across the AlN film, the most conductive SiC materials were sought out for AlN deposition trials, with reactionbonded excluded from the trials because of the free silicon. 
Initial deposition trials were performed on an unknown $\mathrm{SiC}$ material remaining from an unrelated program. Early results were encouraging, with good film adhesion, but only a weak ultrasonic signal. Low electrical conductivity of the $\mathrm{SiC}$ was suspected, and an investigation of higher-conductivity $\mathrm{SiC}$ was begun. Additional films were deposited on three additional $\mathrm{SiC}$ materials: Hexoloy SG, a sintered material produced by Saint-Gobain Ceramics; Pure SiC-LR, a CVD material from Coorstek Ceramics; and Performance SiC, a CVD material from Morgan Advanced Ceramics. Figures 5-8 show films successfully deposited on the various $\mathrm{SiC}$ substrates. No special surface conditioning or preparation was required to achieve adhesion on

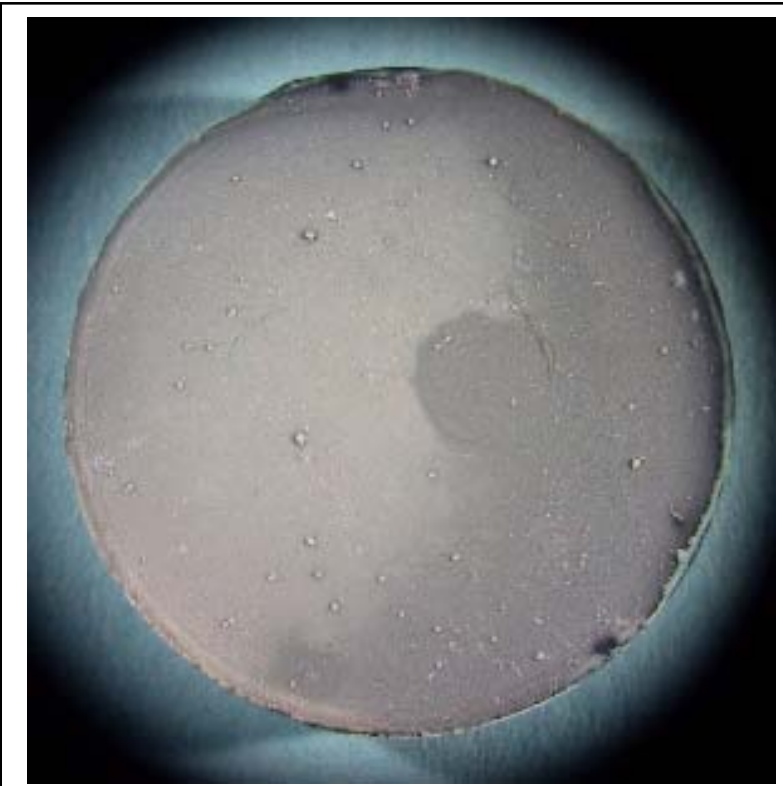

Figure 5. As-deposited AlN film on SiC.

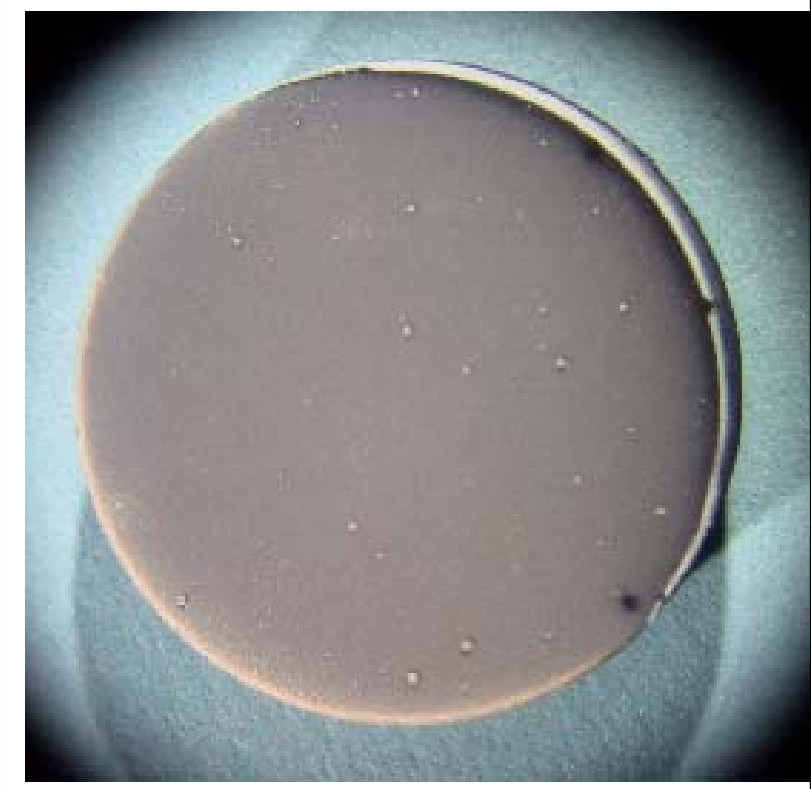

Figure 7. As-deposited AlN film on Pure SiC-LR.

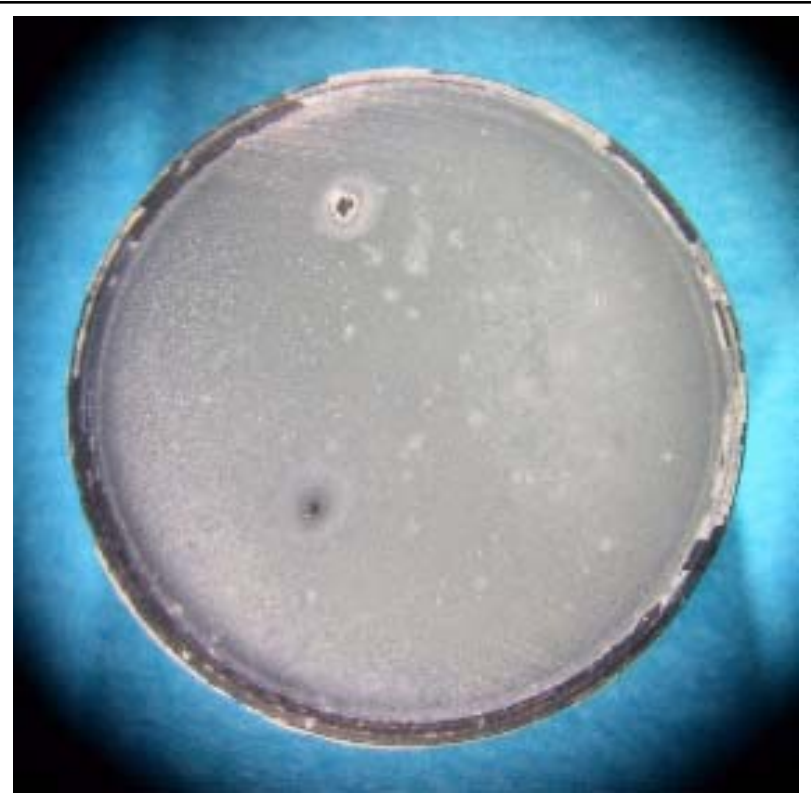

Figure 6. Rough-polished AlN film on Hexoloy SG.

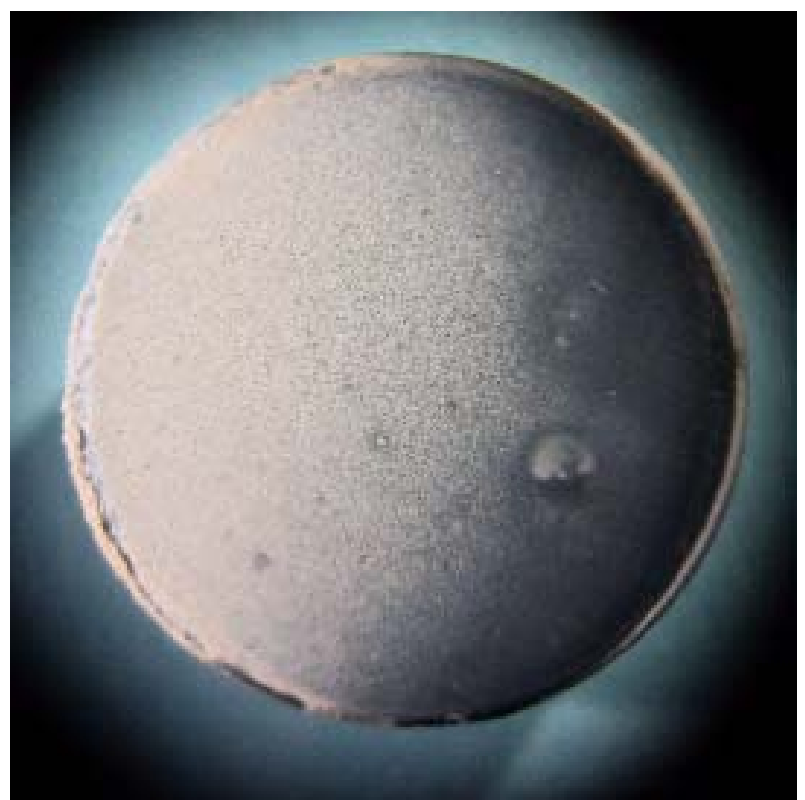

Figure 8. As-deposited AIN film on Performance SiC. 
these materials. At least two films were attempted on each material; films deposited on Pure SiC- LR, had the best adhesion, but all materials showed reasonable adhesion. Additional depositions on WC were also performed in the second year of the program. Later experiments, discussed below, showed that the adhesion is not maintained when the substrate/film is thermally cycled. As a result, two additional substrate materials were investigated. The first was a cobaltcoated $\mathrm{SiC}$, with the intent being to replicate some of the surface chemistry of the tungsten carbide. This coating was unsuccessful; the AlN spalled from the surface immediately, as shown in Figure 9. A second material was an electrically conductive grade of AlN procured from NGK Insulators. Deposition on this material was successful and the film is show in Figure 10. The AlN substrate was not further pursued because, like WC, it is not more oxidation-resistant than the piezoelectric AlN films.

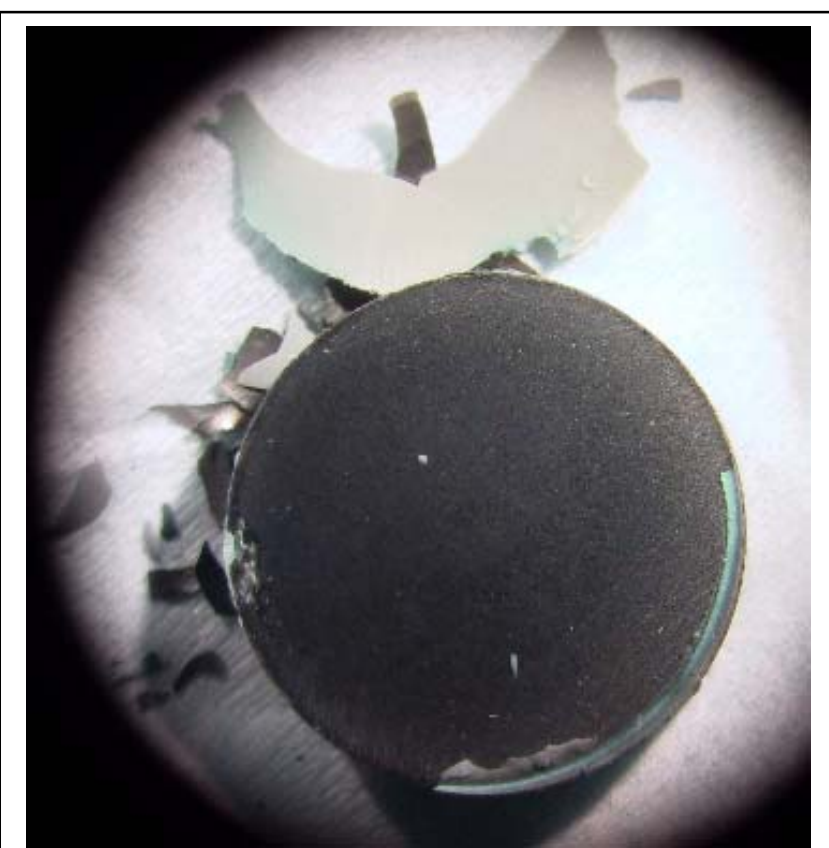

Figure 9. AlN film spalled from cobalt-coated $\mathrm{SiC}$

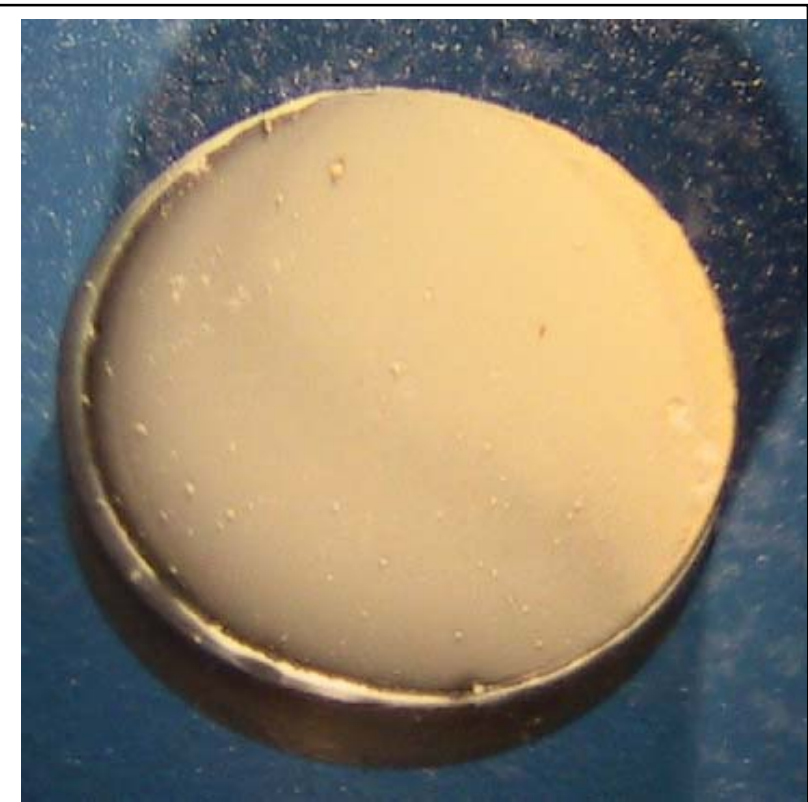

Figure 10. As-deposited AlN film on conductive bulk AlN substrate.

Film deposition in the third year of the program attempted to overcome the disbonding problem by using a porous $\mathrm{SiC}$ substrate material, produced by Saint Gobain. The porosity was expected to provide surface roughness to increase the mechanical bond of the AlN with the surface of the substrate, providing improved film adhesion. In addition, pores in the bulk of the material would scatter the sonic energy projected back into the substrate, reducing or eliminating back surface echoes.

Two different forms of the material were investigated- porous $\mathrm{SiC}$ as described above, and siliconized porous $\mathrm{SiC}$ which had been infiltrated with molten elemental silicon. An initial deposition on both $\mathrm{SiC}$ materials was promising. The films were well adhered and piezoelectric. The $\mathrm{SiC}$ was conductive enough to provide a back surface electrode. The non-infiltrated porous substrates scattered and attenuated the ultrasonic energy to the point that a coherent back surface echo could not be detected. Initial films are shown in Figure 11, and an ultrasonic signal from a film reflected from the back of a test block is shown in Figure 12. Applying a thermal cycle to 
several films quickly indicated that the AlN bonding to the siliconized $\mathrm{SiC}$ was poor, while the porous material continued to show promise. Thermally cycled films are shown in Figures 13 and 14.

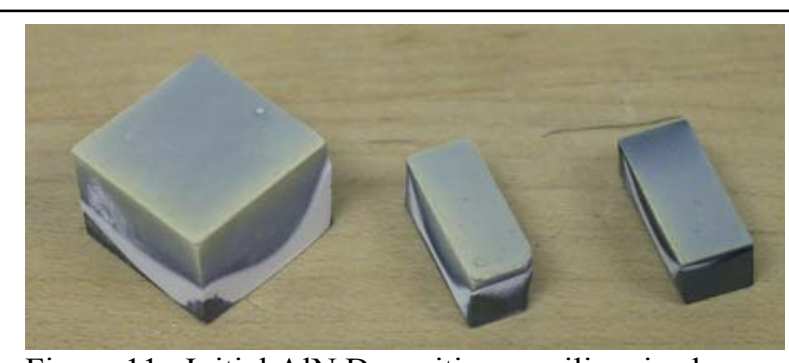

Figure 11. Initial AlN Deposition on siliconized (square) and porous $\mathrm{SiC}$ (rectangular).

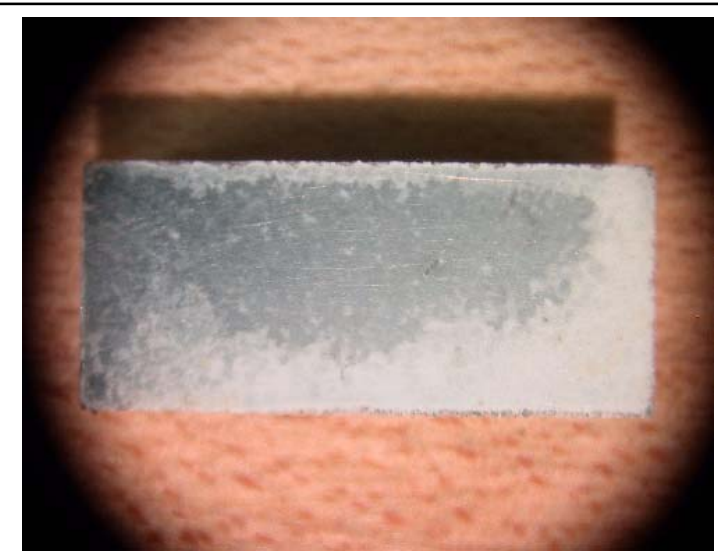

Figure 13. AlN film on porous $\mathrm{SiC}$ after $700^{\circ} \mathrm{C}$ thermal cycle and polishing.

The next step was to obtain additional porous $\mathrm{SiC}$ in the sizes and shapes more desirable for transducer work. A sheet of material was obtained, and cylinders were cut out by abrasive waterjet. AlN deposition on these cylinders was successful and initial adhesion was good, as with the earlier samples. However, as with the other forms of SiC, adhesion was not maintained consistently upon thermal cycling. Varying the surface condition through additional polishing did not solve the adhesion issue. Figures 15 and 16 show an as-deposited film and a film after cycling to only $200^{\circ} \mathrm{C}$ that exhibited a typical, patchy failure mode.

A flame spray coating of WC-Cobalt was applied to a WC substrate in an effort to promote adhesion; but AlN deposition was unsuccessful and this process was not carried over to $\mathrm{SiC}$ substrates. After the analysis of the films discussed below, further film deposition efforts were halted in favor of researching alternatives to the AlN films for high temperature piezoelectric sensor cores.

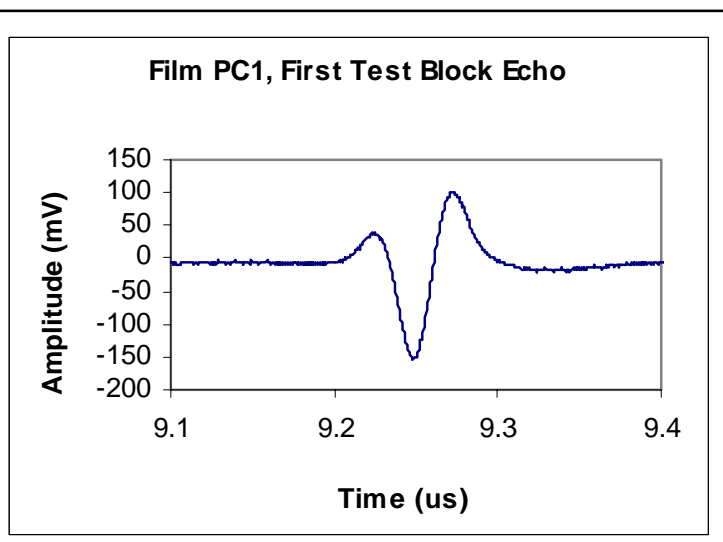

Figure 12. Wideband ultrasonic signal produced by AlN film on porous SiC substrate

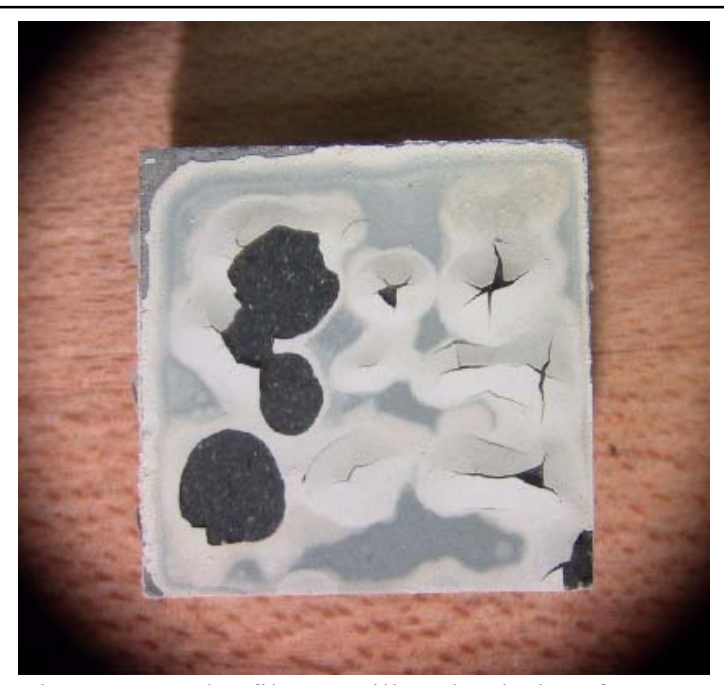

Figure 14. AlN film on siliconized $\mathrm{SiC}$ after $700^{\circ} \mathrm{C}$ thermal cycle. 


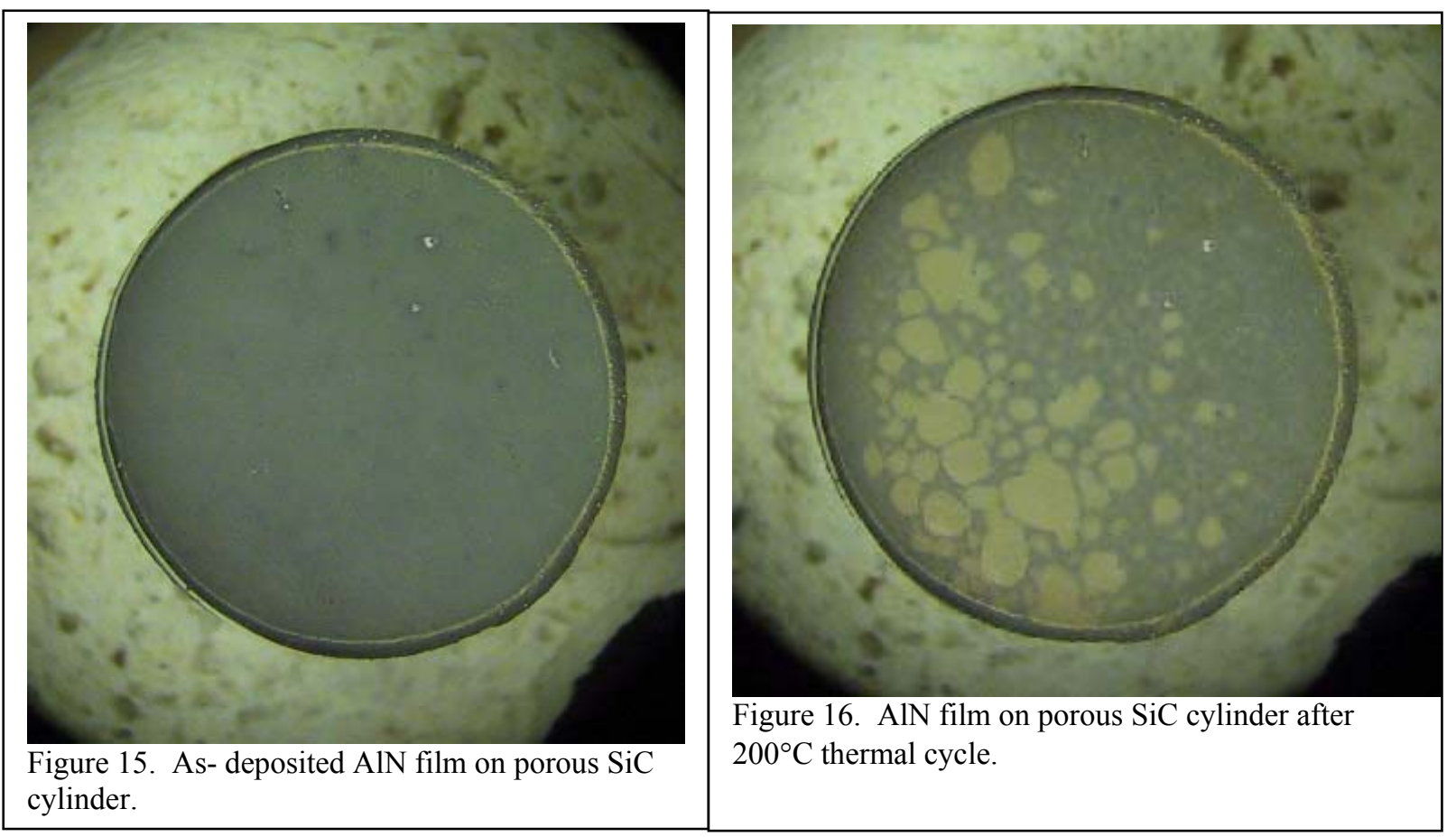




\section{Piezoelectric AlN Film Evaluation}

A major part of the film evaluation has been physical evaluation, primarily film adhesion to the substrates. The thin $(<0.1 \mathrm{~mm}) \mathrm{AlN}$ is not strong enough to be handled unsupported upon separation from a substrate. The CVD process was able to create well-bonded AlN films on tungsten carbide at the start of the project, but the bond strength on other substrate materials needed to be evaluated. The first test was simply time: some films had been known to delaminate during initial cooling while still in the CVD deposition reactor. Other films might delaminate in the following hours or days. This was the case with the films on Grade 5 titanium, so no further evaluation was possible.

If a film was stable, an initial polish as described above was performed prior to initial ultrasonics testing. Often films were received with a raised rim of AlN that was not well bonded, breaking off and leaving exposed substrate at the edge of the film. While not desirable, this rim was not detrimental to film use. However, some of these films would continue to delaminate with time, primarily on titanium. An additional test was to slowly heat the substrate using a hot plate. The films on tungsten carbide survived this as in the past, but no AlN films on titanium survived a single heating and cooling cycle, as shown in Figure 17. Note the two phase delamination of the film: this occurred in some, but not all films. The thin lower layer in the bottom of Figure 17 was found to be dense and well bonded, while the thicker upper layer exhibited some porosity. This dual-natured coating was discovered to be typical of the depositions.

The AlN films on $\mathrm{SiC}$ showed mixed results. Most films exhibited good initial adhesion, as shown in Figures 5-8. Some of these were rather weakly bonded, however, and underwent significant damage or delamination upon polishing. Figure 18 shows a typical example with edge damage and a delamination (white area) extending from under a pore. Figure 19 shows more severe damage incurred on a different $\mathrm{SiC}$ material. The Hexoloy SG and Pure SiC-LR materials both showed acceptable adhesion and were further evaluated for ultrasonic properties and

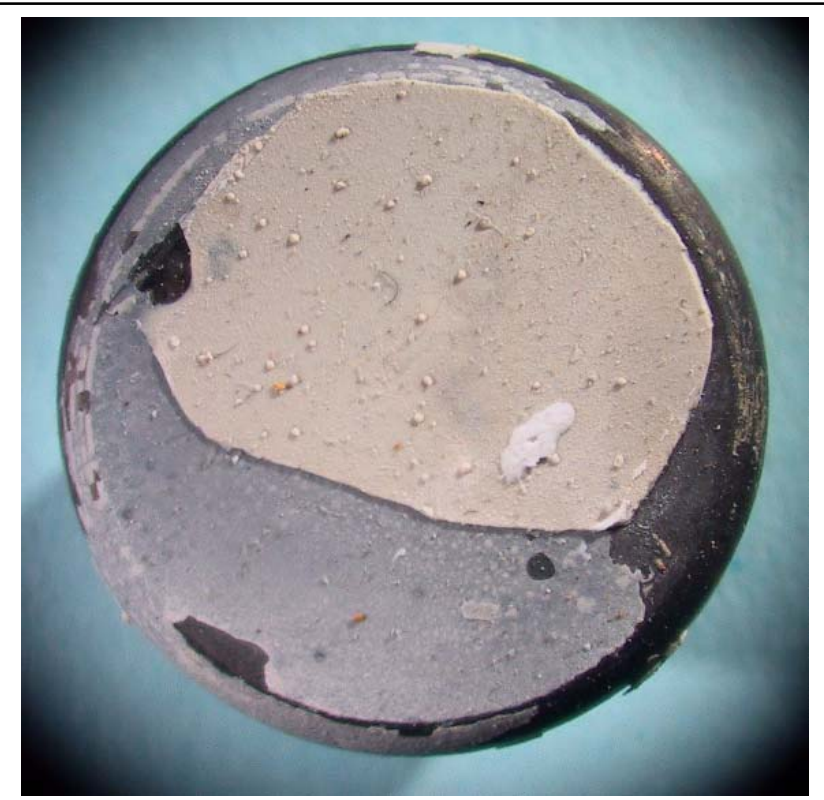

Figure 17. AlN film on Ti delaminated by heating. thermal cycling resistance.

Both materials showed poor adhesion upon thermal exposure. Delaminations usually began at an edge or existing defect, and spread quickly under the film, which split and buckled. Figure 20 shows the same film as Figure 18 , after polishing and heating to only $400^{\circ} \mathrm{C}$. The pore in Figure 18 is at the top of Figure 20, just left of center. The darker areas are still well adhered, but more than half of the film has delaminated and cracks are visible in the center of these regions. An 
AlN film on Pure SiC-LR, which had only minor edge delamination prior to heating, experienced even more severe damage. Figure 21 shows this film before and after heating.
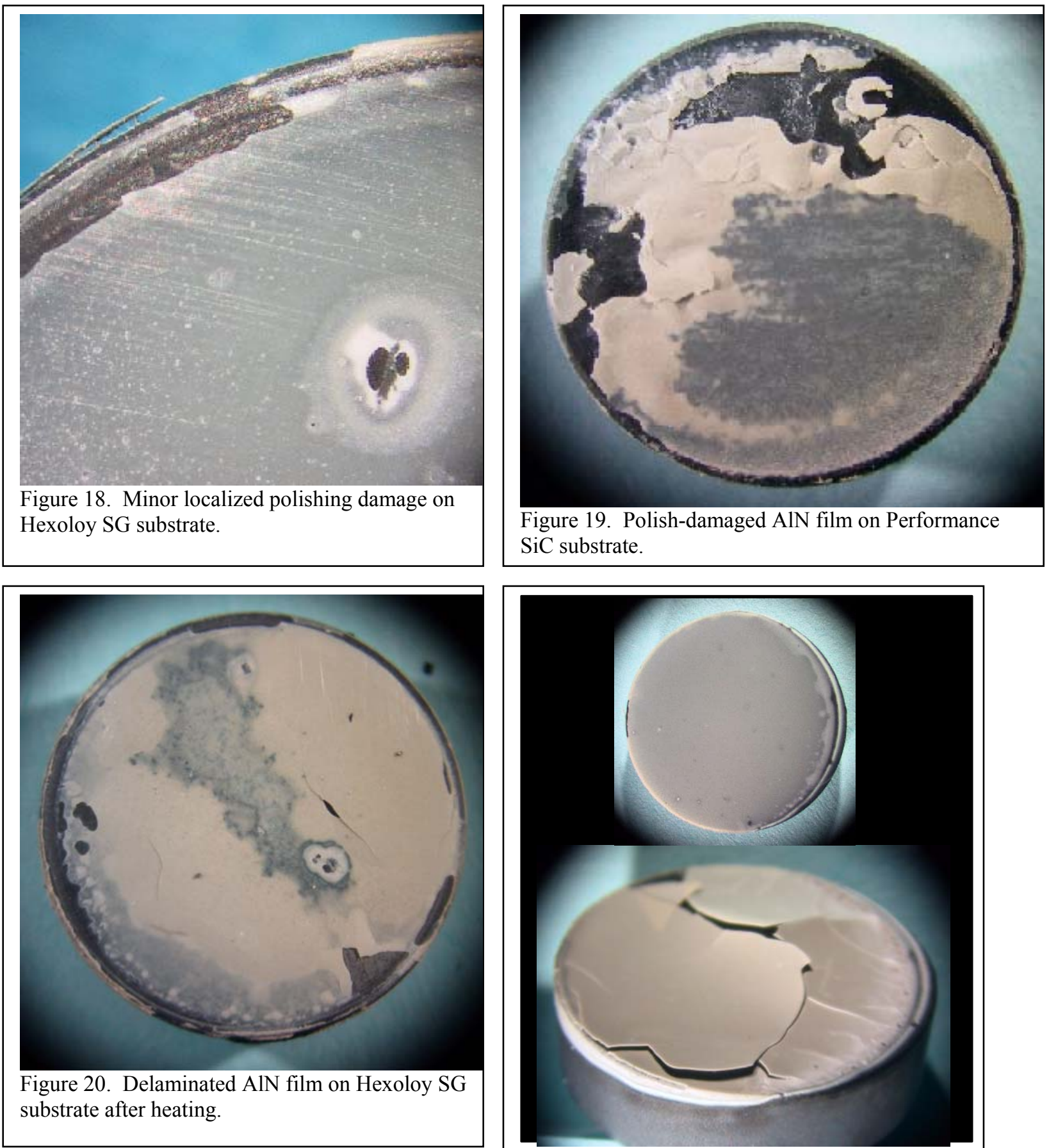

Physical evaluation, embodied as film

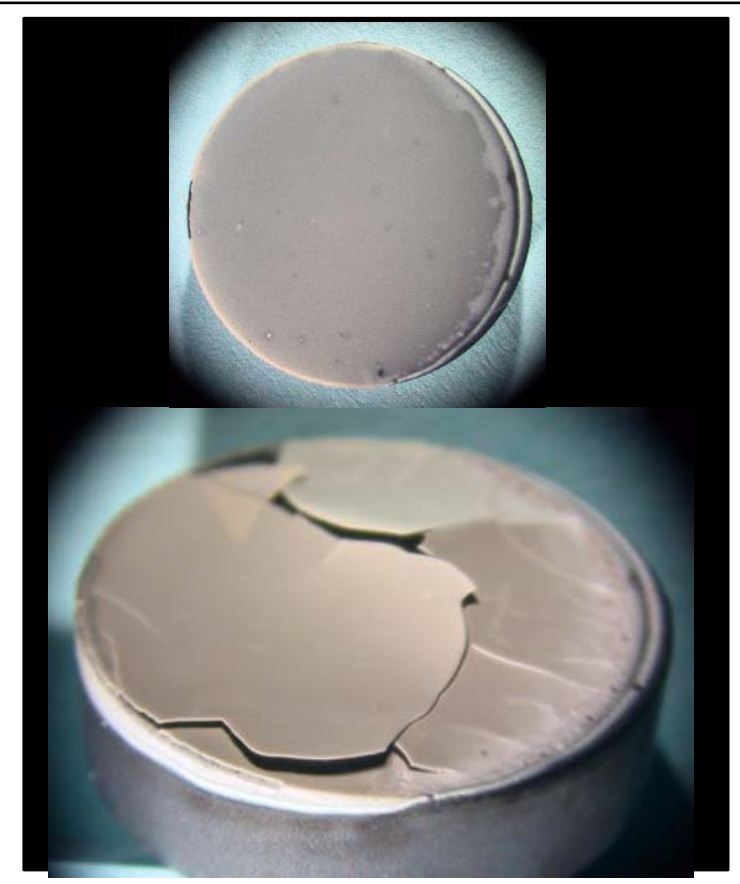

Figure 21. Massively delaminated AlN film on Pure SiC-LR substrate before and after heating.

adhesion to the substrate, became the primary evaluation criteria for the films on porous $\mathrm{SiC}$ because disbonding during thermal cycling was the predominant failure mode. Most films had good coverage, few or no pinhole defects, and were oriented to be piezoelectric. Film failure from thermal cycling occurred universally. The onset of damage varied, usually in the $200^{\circ} \mathrm{C}$ to $500^{\circ} \mathrm{C}$ range, although some 
films maintained adhesion to $700^{\circ} \mathrm{C}$ for one or two cycles. Analysis, consisting of micrographic sectioning and chemical analysis, was performed. It was determined that the AlN deposition was actually occurring in two distinct phases, consisting of a thin, dense layer, followed by a more porous outer layer as shown in Figures 22 and 23. The cracks in a plane parallel to the surface of the substrate visible in Figure 23 were noted in all the samples evaluated.
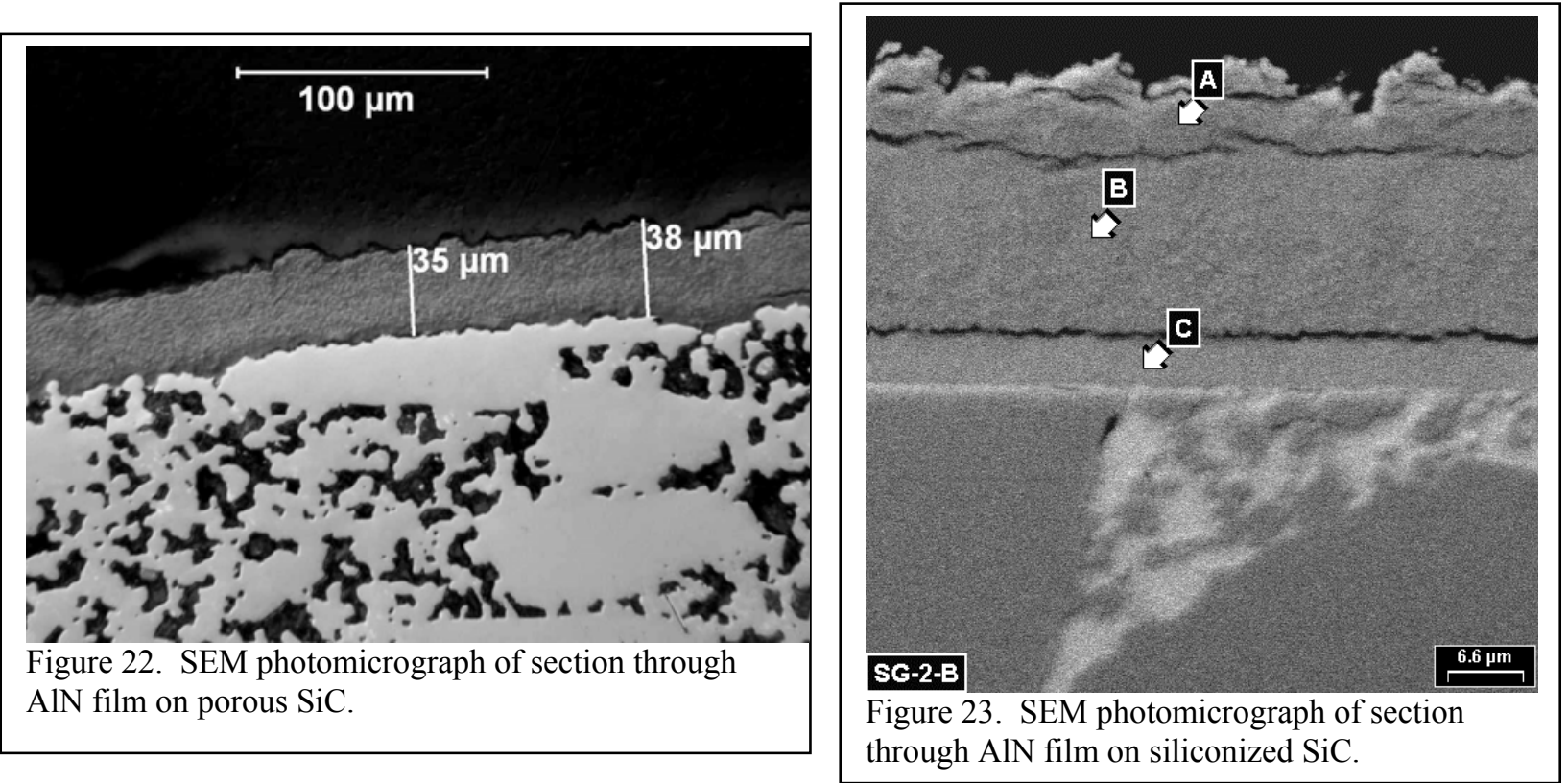

Additional analysis was performed on the surface of substrates where films had failed due to thermal cycling. Elemental analysis revealed the presence of a substantial amount of oxygen on the surface, likely bound in silicon dioxide. The deposition process was reviewed to insure that oxygen contamination was not occurring during substrate heating and deposition, but no source of contamination was found. Samples prior to thermal cycling were also evaluated using SIMS/Auger to check for contamination after deposition. Table 1 shows the results, indicating that oxygen is present at the surface of the AIN but the concentration quickly falls off with depth. The remaining concentration is still enough to be of concern.

\begin{tabular}{|c|c|c|c|c|c|}
\hline \multirow{2}{*}{$\begin{array}{c}\text { Auger } \\
\text { Sample }\end{array}$} & \multicolumn{5}{|c|}{ Relative Atomic Concentration (\%) } \\
\hline & $\sim$ Depth & $\mathbf{C}$ & $\mathbf{N}$ & 0 & $\mathrm{Al}$ \\
\hline & $1000 \mathrm{~A}$ & 4.15 & 22.61 & 25.47 & 47.77 \\
\hline AIN Coated & $5000 \mathrm{~A}$ & 9.70 & 25.73 & 10.45 & 54.12 \\
\hline \multirow[t]{4}{*}{ SiC } & $1.5 \mathrm{um}$ & 2.06 & 28.32 & 10.80 & 58.83 \\
\hline & $2.5 \mathrm{um}$ & 1.58 & 29.94 & 10.66 & 57.83 \\
\hline & $4 \mathrm{um}$ & 0.95 & 30.57 & 11.47 & 57.01 \\
\hline & $10 \mathrm{um}$ & 1.39 & 30.65 & 6.57 & 61.39 \\
\hline
\end{tabular}

The X-ray diffraction spectrum of a typical AIN film on SiC, shown in Figure 24, indicates it is composed primarily of oriented AlN, with a possible $\mathrm{Si}-\mathrm{Al}$ intermetallic phase as a minor component, probably due to reaction with the free silicon.

The SEM allowed the discovery that even films that appeared to survive initial thermal cycles did not do so without substantial microscopic damage. Figure 25 shows the surface of an AlN 


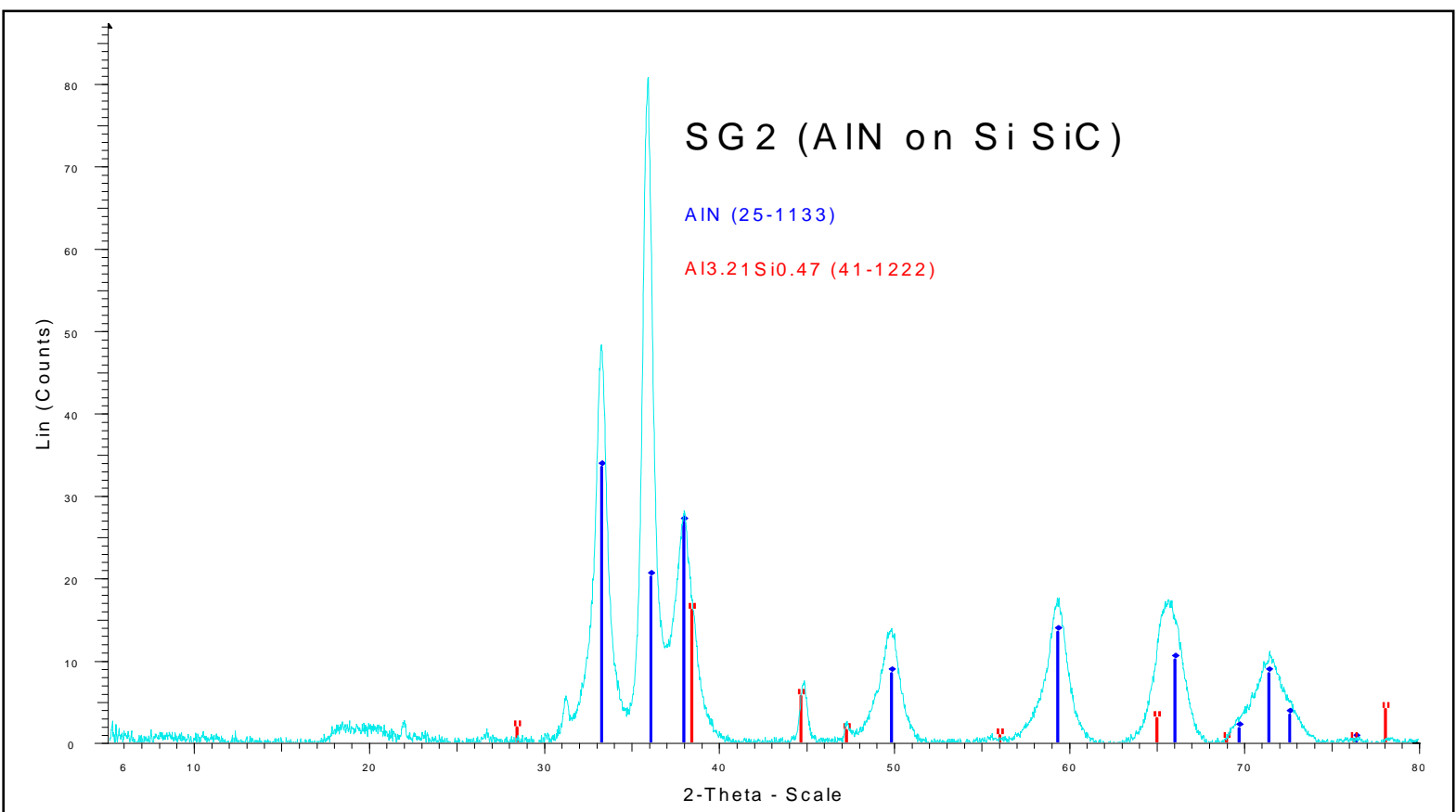

Figure 24. XRD analysis at surface of AlN film.

film on siliconized $\mathrm{SiC}$ before and after a thermal cycle to $1050^{\circ} \mathrm{C}$ in an inert (argon) atmosphere. The presence of this sort of damage indicates that oxidation from the atmosphere is not a requirement for the damage to occur. The cracking pattern may indicate the boundaries between individual crystal grains, suggesting that thermal strains arise, stressing the film-substrate bond.

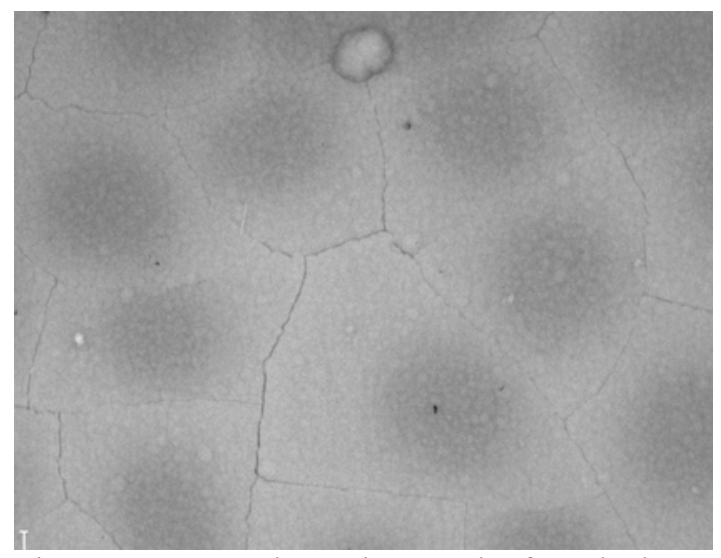

Figure 25. SEM photomicrograph of cracked AlN film on siliconized SiC after thermal cycle. 
Finally, testing for ultrasonic properties was performed, generally before a heating test. A Utex 340 ultrasonic square wave pulser/receiver instrument was used with an Agilent 54622A digital oscilloscope for these tests. Figure 22 shows the Utex 340 incorporates programmable low pass and high pass filtering, and can supply pulses of 5-80 ns with an amplitude of 100 to $500 \mathrm{~V}$. Test voltages near $300 \mathrm{~V}$ were used for most films unless electrical shorting near damaged areas forced the use of lower voltages. For most testing, the film was placed on water-based ultrasonic couplant on a flat metal electrode. A two pronged probe from the pulser/receiver was then touched to this stack, with the ground on the metal electrode and the signal lead on the film's substrate. Pulse width, gain, and receiver filters were adjusted to maximize the signal on a film-to-film basis.

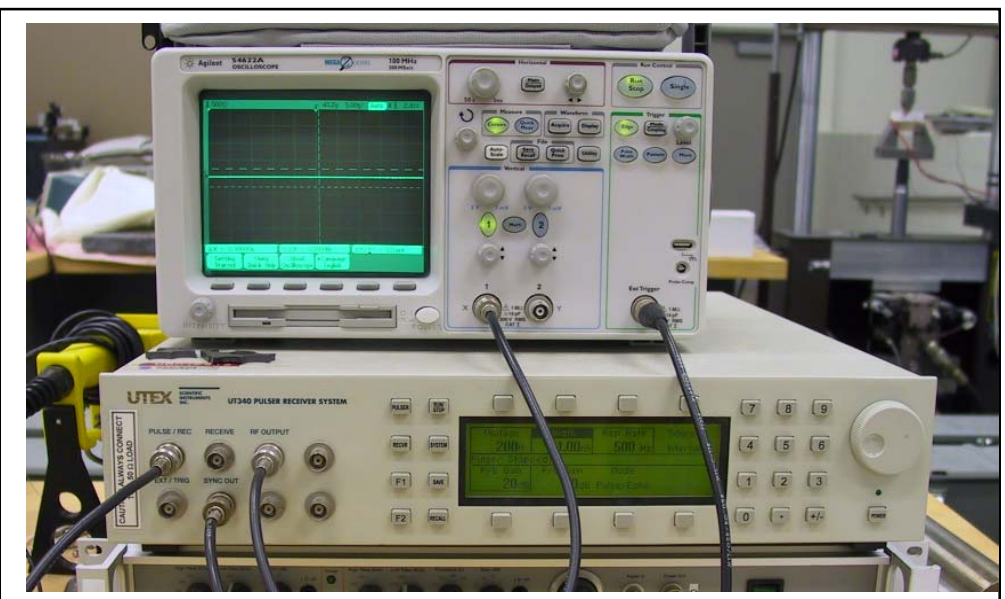

Figure 22. Utex 340 Pulser-Receiver and Agilent Oscilloscope.

The frequency content of the first clear echo from the back of the substrate was used to determine the natural frequency of the films. The echo from the far surface of a $25.4 \mathrm{~mm}$ thick, $17-4 \mathrm{PH}$ stainless steel cylinder with parallel faces, used as the metal ground electrode, was also used to provide a film-to-film strength comparison without effects from the substrate geometry. Pulse width and gain settings were adjusted as needed. Averaging of multiple pulses was used to increase the signal to noise ratio. A typical ultrasonic waveform is shown in Figure 23.

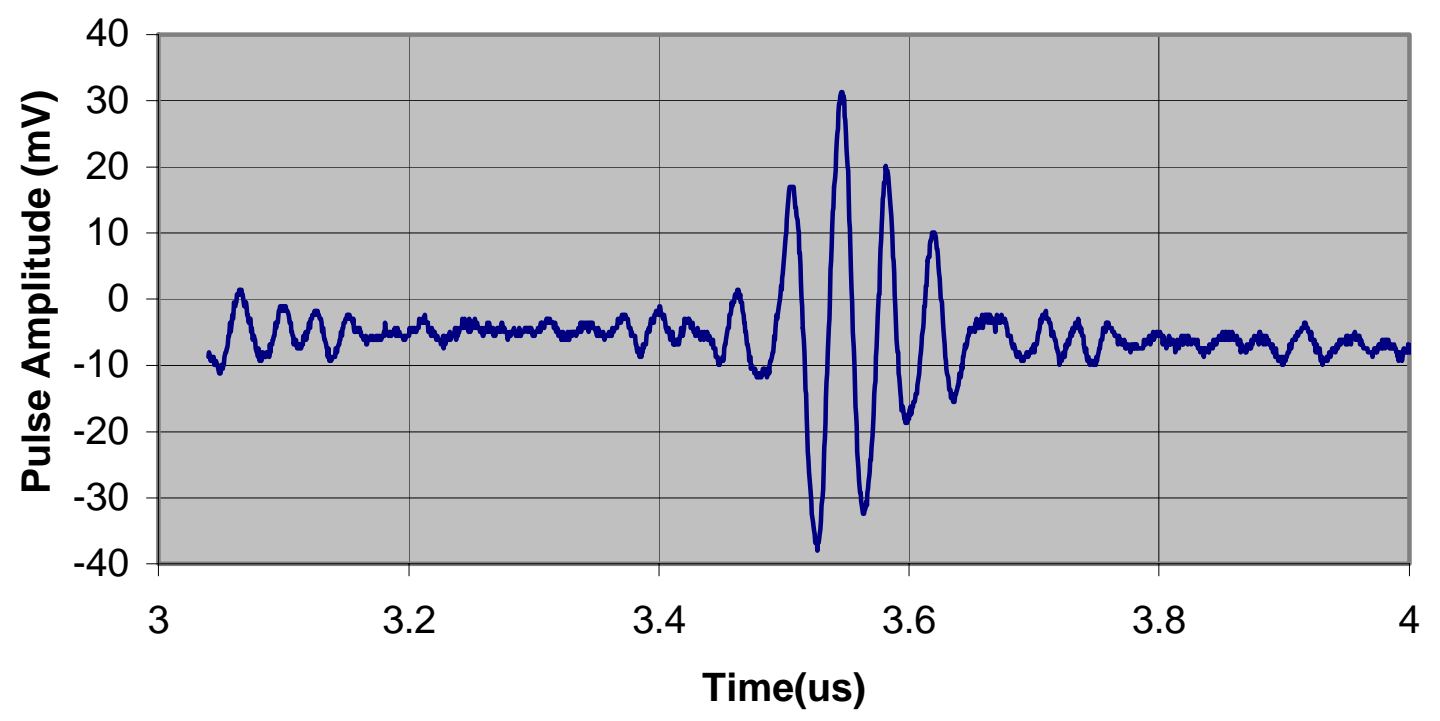

Figure 23. Typical ultrasonic pulse produced and received by AlN film. 
Initial results with AlN films on $\mathrm{SiC}$ were disappointing but showed promise. The films were producing ultrasonic energy, but weakly. Further polishing of both the AlN films and the back surface of the $\mathrm{SiC}$ substrates did not improve the signal strength. Time-averaging was used to improve the $\mathrm{S} / \mathrm{N}$ ratio of the ultrasonic signal. A breakthrough was made in signal strength when it was discovered that the marginal electrical conductivity of the $\mathrm{SiC}$, combined with an oxide layer in some cases, was leading to an unacceptably high lead resistance between the substrate and the ultrasonic pulser-receiver. This was overcome by placing a metal disk against the back of the substrates to act as a wide electrode. Signal strength improved by $\sim 20 \mathrm{~dB}$, producing ultrasonic signals similar in amplitude to those form AlN on WC, but with substantially better bandwidth. The results section below contains details of the ultrasonic evaluation.

Some of the failed films were subjected to EDS analysis to try to determine the failure mode after delamination. Early AIN films on WC that delaminated had been found to actually pull some WC material off the surface of the substrate, indicating a strong bond. AlN films delaminated from titanium metal were found to have two distinctive layers, with an interface layer that remained attached in some cases, and a bulk AlN layer which spalled. This was not the case for the various films on SiC- the AlN separated cleanly from the SiC.

As before, testing for ultrasonic properties was performed on "good" films on porous $\mathrm{SiC}$ substrates, using the same apparatus and methodology described in the previous report. The echo from the back surface of the porous substrate was too highly attenuated to be useful, for measurement and so all data for films on porous $\mathrm{SiC}$ was taken on test blocks, such as the $\sim 25$ $\mathrm{MHz}$ pulse shown in Figure 23. The rapid attenuation of received pulses from two successive echoes is shown in Figure 24. Ultrasonic evaluation of the films on porous substrates was used primarily to show that the films were active before subjecting them to thermal cycling; these films were similar in strength and frequency content to earlier films on tungsten carbide, titanium, and solid $\mathrm{SiC}$ substrates.

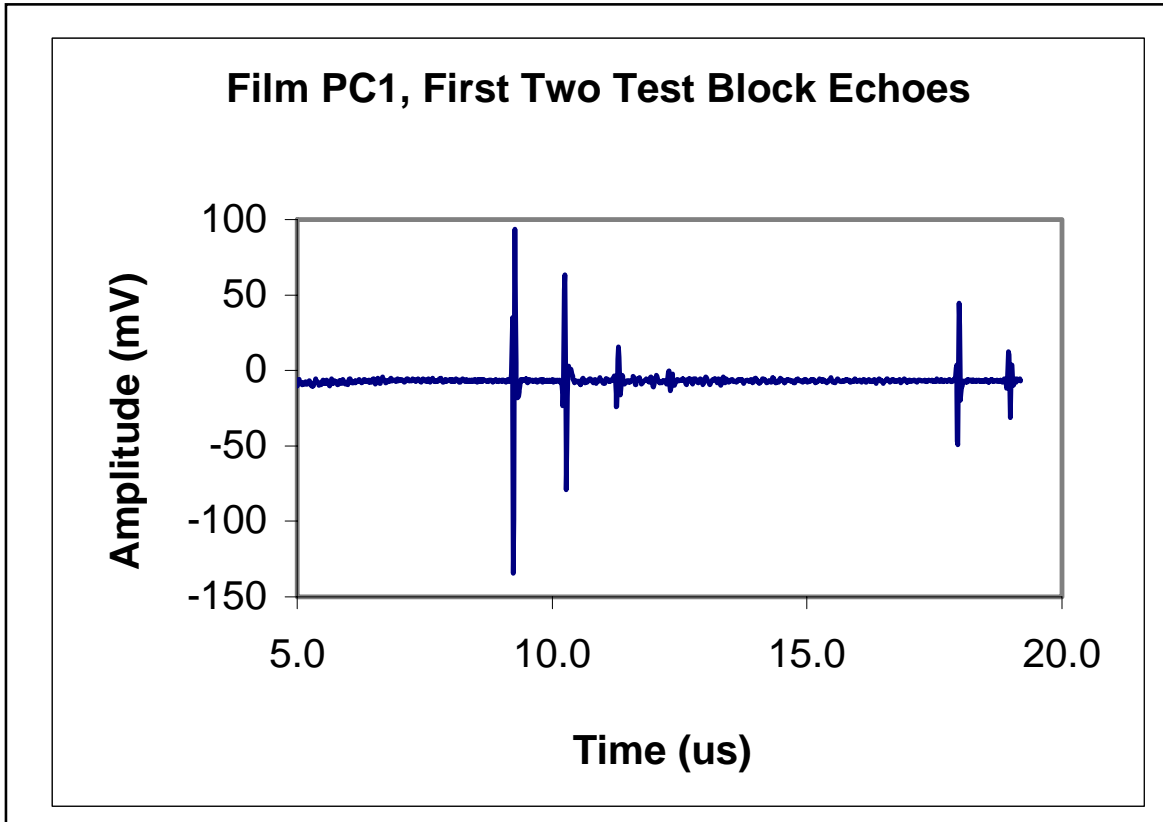

Figure 24. Ultrasonic signal produced by AlN film on porous SiC substrate, showing rapid attenuation of ringing in substrate after reception of each pulse 


\section{High Temperature Ultrasonic Coupling}

Based on information gathered in the literature survey during the first year of the program, high temperature coupling experiments were designed to evaluate the use of molten glass and metal foil to couple ultrasonic energy between a transducer and a test object. Successful high temperature ultrasonic coupling is required for overall program success; commercial ultrasonic couplants are not marketed for use at these temperatures because ultrasonic transducers for very high temperatures are also not currently marketed.

The most basic coupling experiment was to test the molten glass coupling. Two electric resistance band heaters encircling a $25 \mathrm{~mm}$ diameter test cylinder $100 \mathrm{~mm}$ long provided heat. A $\mathrm{K}$-type thermocouple welded to the cylinder near the top measured temperature. Powdered glass was placed on the cylinder, followed by an AlN film on a WC substrate. A second thermocouple welded to the substrate provided a second temperature measurement, and the interface temperature was estimated to be the average of these two thermocouples. Another stainless steel cylinder, this one only $25 \mathrm{~mm}$ long, was placed on top to provide a small compressive load to the interface. This entire test stack was generally wrapped with an insulating blanket to accelerate the heating time and to maintain a more uniform temperature.

To transmit and receive ultrasonic energy, the thermocouple wires were disconnected from the temperature readout and connected instead to the Utex pulser/receiver, with the large cylinder acting as the ground and the substrate thermocouple acting as the signal lead. Upon heating past its melting point, the powdered glass liquefied and did function as an ultrasonic couplant. While the AlN showed some signs of chemically reacting with the glass, it was not physically damaged by the resolidification of the glass.

In order to test metal foil coupling, the same apparatus and procedure were followed, except that a larger compressive load was required; a servohydraulic load frame with water-cooled compression platens applied this load as shown in Figure 25. Ceramic and mica sheets placed between the platens and the test stack described above prevented the rapid conduction of heat into the cooled platens. A spherical washer at the top platen accounted for any misalignment in the test stack. While the load frame used in the experiments was capable of applying $500 \mathrm{kN}$, the lowest range was selected and the largest force used in this testing was $12 \mathrm{kN}$. After the load was set, the servohydraulic controller maintained the load, accounting automatically for displacements caused by thermal expansion when the test stack was heated. Aluminum, silver, and gold foils were tested for coupling.

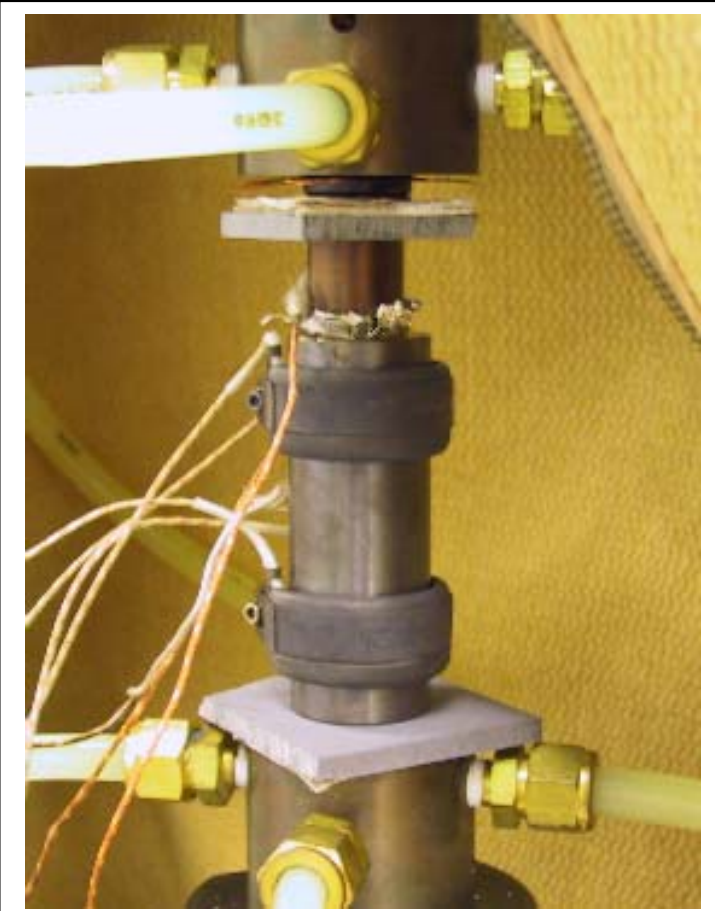

Figure 25. Coupling test stack in load frame. 
Gold foil was initially used for coupling, but investigation continued in search of a more economical material. Gold leaf, used by artists and architects to apply a very thin coating of true gold to objects, was obtained. The $24 \mathrm{k}$ leaf is extremely thin $(0.1 \mu \mathrm{m})$ and is thus much less expensive than foil $(\sim 25 \mu \mathrm{m})$. A book of gold leaf such as the one in Figure 26 costs less than $\$ 100$ and contains $\sim 1800 \mathrm{~cm}^{2}$ of gold leaf. Several layers of gold leaf between objects provided good ultrasonic coupling, similar to foil. Handling the leaf is more difficult, however, as it is very delicate. For this reason, plain loose gold leaf was found to be superior to "patent" gold leaf, which is sold adhered to tissue paper for support during handling but is difficult to remove from the paper when not adhered to something else. No adhesives could be used in this work due to the high temperatures involved, and easily evaporated liquids such as water and methanol did not work as alternatives.

\section{New Crystal Acquisition and Testing}

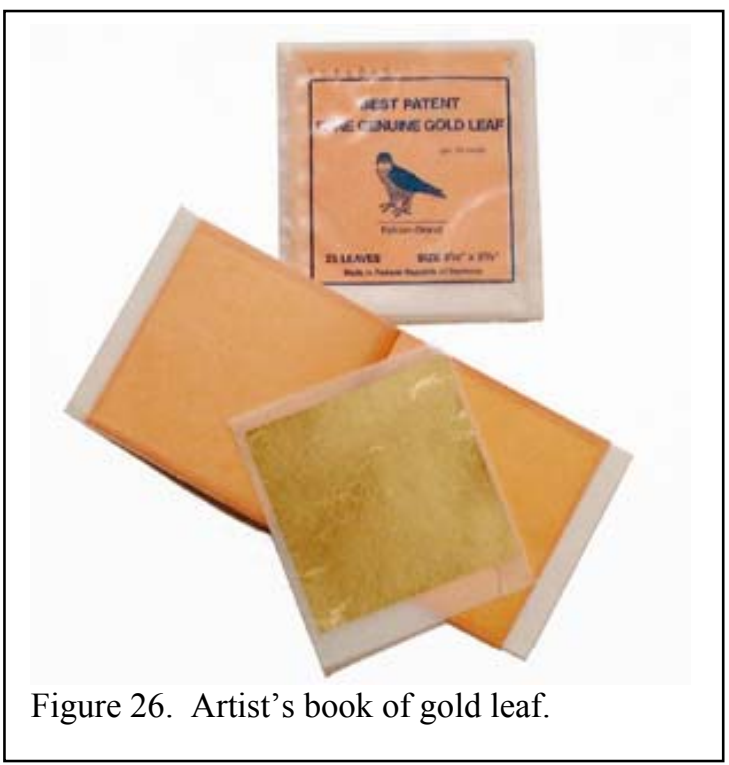

While the overall goal of the program was a high temperature sensor, much of the research in the first 2.5 years of the program focused on advancing the sensor core technology, consisting of a piezoelectric AlN film deposited on a conductive substrate. Because of the difficulties encountered in AIN film deposition, a reexamination of this approach yielded two possible alternatives. The first alternative was to procure single crystal AlN, but this technology did not yet appear to be practical, with only very limited production available, very expensive for future transducer production, and dedicated to the semiconductor industry.

A second single crystal material with potential is Langasite (LGS), $\mathrm{La}_{3} \mathrm{Ga}_{5} \mathrm{SiO}_{14}$, a synthetic crystal material. LGS is very chemically stable at elevated temperature and undergoes no phase transformations until it melts at $1470^{\circ} \mathrm{C}$. It has the same crystal structure as alpha-quartz, making it piezoelectric, but the lack of a phase transformation prior to melting means that it has no Curie temperature like quartz. It is available commercially from multiple sources at reasonable cost, and crystals may be obtained cut to any desired thickness and in several orientations. Substituting LGS for the AIN in sensors was determined to have the potential to operate at or beyond $1000^{\circ} \mathrm{C}$ for extended periods of time, even in an oxidizing atmosphere.

Samples of LGS were procured from two sources, Axtal (Germany), and Mitsubishi Electronic Materials (Japan). Figure 27 shows a Mitsubishi crystal, which is the translucent orange color typical of the LGS. The same crystal in Figure 28 , has been cycled to $700^{\circ} \mathrm{C}$ with no apparent oxidation or other effects, and no degradation in signal strength. To evaluate the piezoelectric behavior with temperature, a test was devised where the crystal was placed on a heated platen, a flat electrode was placed on top, and a voltage pulse was applied across the crystal as it would be 


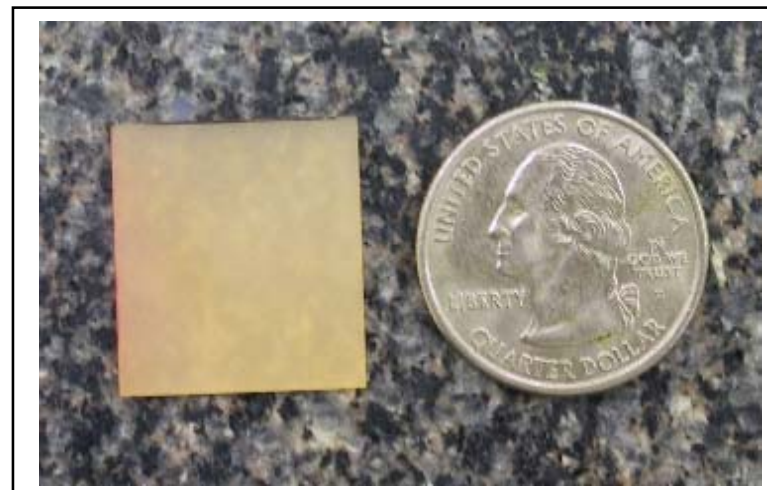

Figure 27. LGS crystal, as received.

applied in an ultrasonic transducer. This induced a free resonant vibration through the thickness of the crystal because it is not ultrasonically coupled to a backing material or test material on either face. These vibrations, shown in Figure 29, indicate that the resonant frequency of the $1.0 \mathrm{~mm}$ thick crystal is about $3 \mathrm{MHz}$. It is therefore acoustically very similar to AlN. The graph in Figure 30 further shows the behavior of this vibration with temperature- the LGS becomes more responsive up to at least $600^{\circ} \mathrm{C}$. This peak value was not consistent between different samples of the material, and may be the result of electrode oxidation or other effects not tied to the crystal itself, or may be a softening of the crystal with temperature. Similar behavior was exhibited by the Axtal material, $0.85 \mathrm{~mm}$ thick.

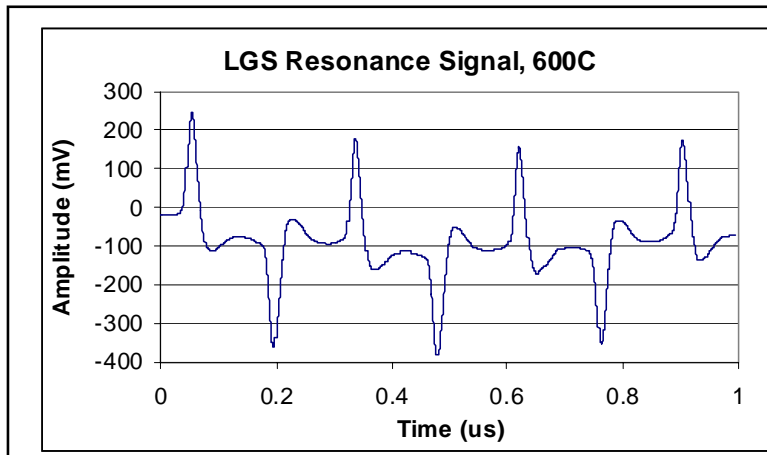

Figure 29. Free vibration piezoelectric resonance in LGS crystal.

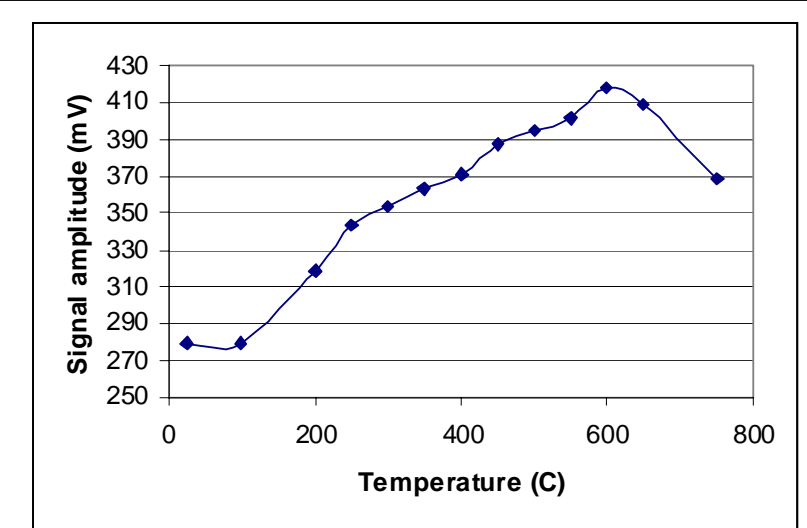

Figure 30. Resonance amplitude in LGS crystal as a function of temperature.

A modified version of this test was used to test up to $1000^{\circ} \mathrm{C}$, and to simulate an equipment health monitoring application. A titanium test block replaced the stainless steel block after oxidation of the steel became excessive at temperatures above $700^{\circ} \mathrm{C}$. Several layers of gold leaf were placed on the block to provide ultrasonic coupling, followed by the LGS crystal, more gold leaf, a SiAlON backing block, and then a steel weight; this stack is shown after the test in the furnace in Figure 31. Electrical connections were made to the titanium block and stainless weight by welding short pieces of Inconel wire between the blocks and the Thermocoax signal cable, visible on the left side of Figure 31. Gold paint (Hanovia Liquid Bright Gold "N") and clay (AGS ${ }^{\text {TM }}$ - Accent Gold for Silver) were previously investigated as a means of applying a high temperature electrical path across an insulator. These were used to convey signals from the stainless weight to the gold leaf on one side of the LGS crystal; the titanium acted directly as the 
electrode on the other side. The twisted wire on the right side of Figure 31 was the thermocouple used to monitor the test temperature. Figure 32 shows the assembly before placing it in the furnace; Figure 33 shows the individual components after the test. Note that the gold leaf has bonded to both surfaces it contacted; the gold leaf and conductors are intact. The LGS crystal and SiAlON backing material showed no degradation.

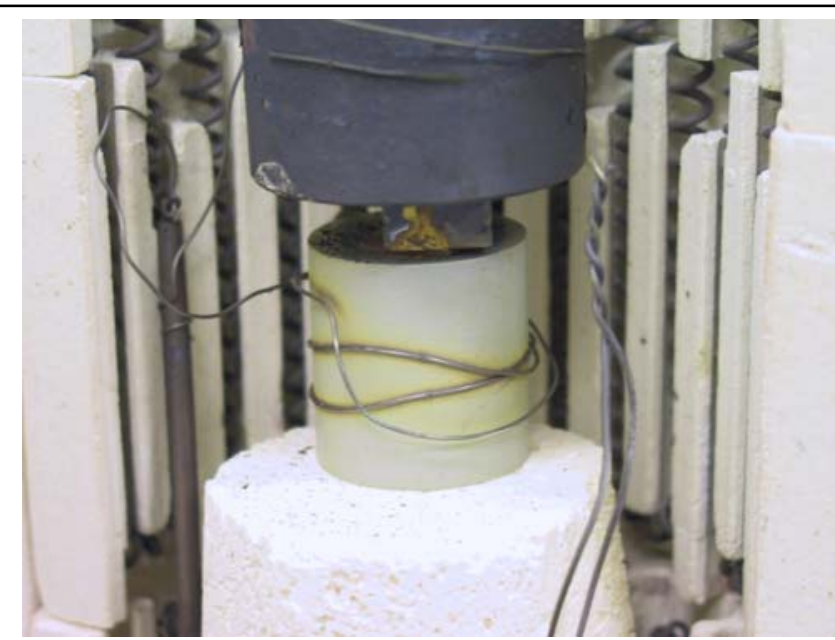

Figure 31. Simulated transducer in furnace after test.

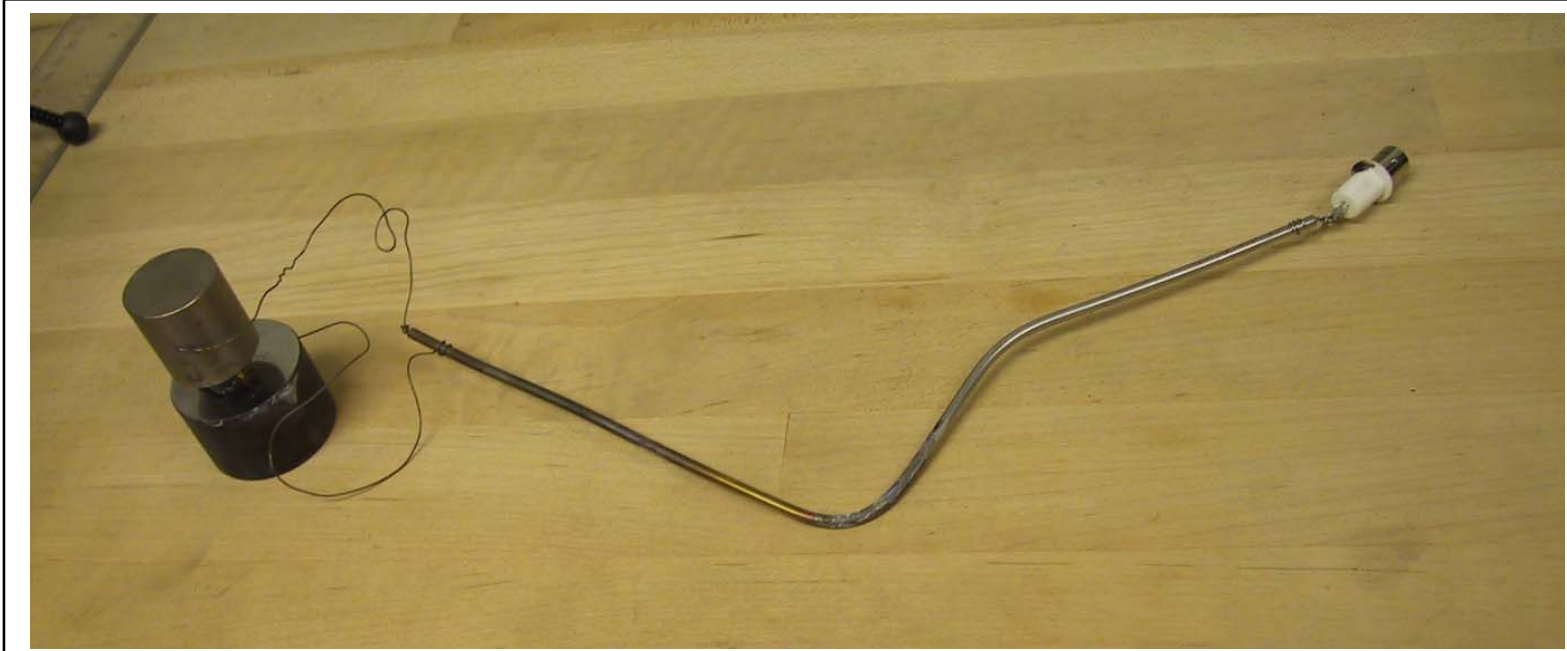

Figure 32. Transducer assembly before test.

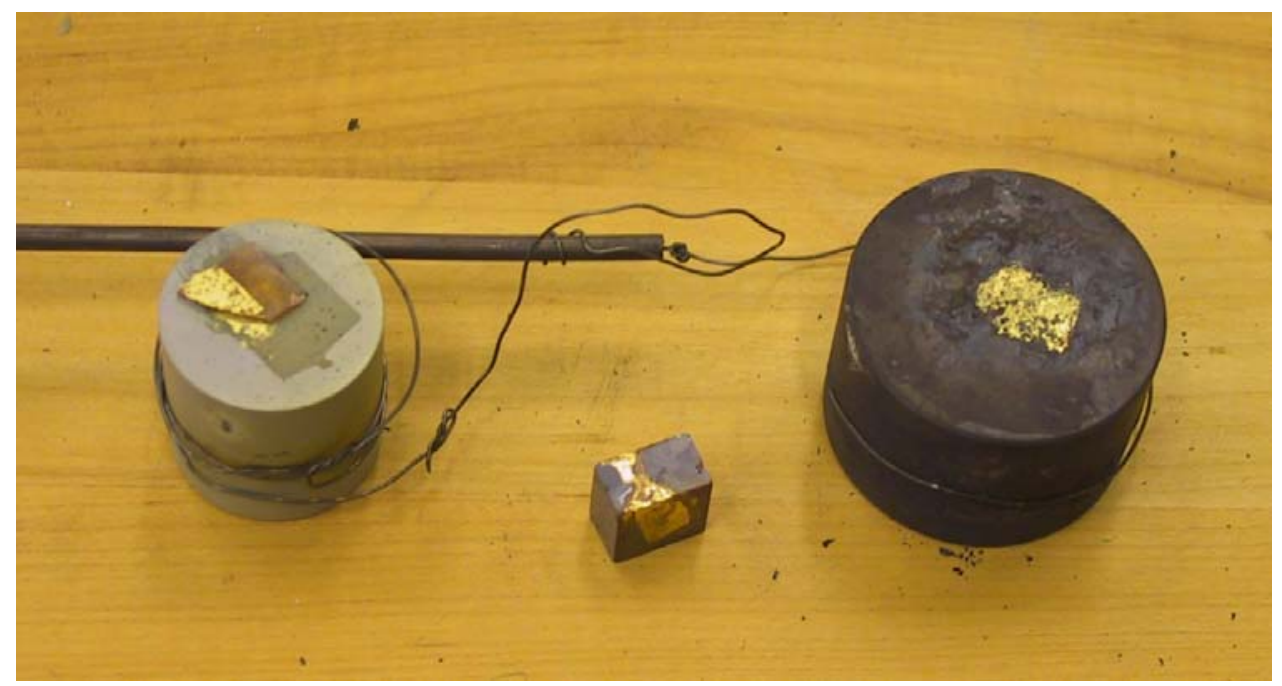

Figure 33. Transducer components after test. 


\section{SECTION 4 \\ RESULTS AND DISCUSSION}

\section{Piezoelectric AIN Film Deposition}

Task Description: The deposition of AIN films onto high temperature substrates will be studied and improvement made with respect to process and yield. Disposition of films will initially be done by an elevated temperature chemical vapor deposition process. An alternative deposition process, pulsed laser deposition (PLD), will also be attempted. Temperature of the substrate and PLD pressure will be varied to create an AIN film with piezoelectric behavior.

Subtask 1A: Conduct deposition of thick AIN film by chemical vapor deposition. Nov 2002May 2005.

The CVD deposition apparatus was brought on-line and reliably produced piezoelectric AlN films on tungsten carbide substrates. Titanium substrates were next used and after a number of experiments with surface finish and several titanium alloys, AlN films were successfully deposited on a titanium substrate. Additional films were created in the second year of the program on tungsten carbide, silicon carbide, and conductive aluminum nitride. In the third year, deposition was expanded to porous and siliconized porous $\mathrm{SiC}$, as described above. Deposition of robust films suitable for sensors was not achieved in the research program.

Subtask 1B: Identify the promising high temperature substrates with regard to thermal expansion, cost, machinability, and the ability to shape the substrate. Nov 2002-May 2004.

An exhaustive search for alternate substrates identified few candidate materials. Titanium metal seemed to be a good candidate because of its machinability, but had too great a difference in thermal expansion rates when reheated after deposition. Films would immediately separate from the substrate after heating to only a few hundred degrees Celsius. Silicon carbide (SiC) was identified as a good candidate for its thermal expansion and oxidation properties, but its electrical conductivity is borderline acceptable for strong piezoelectric operation of the AlN material, and was found to bond poorly with the AlN. Additional materials, including several refractory metals $(\mathrm{Mo}, \mathrm{W})$, carbides $(\mathrm{TiC})$, and conductive ceramics (titanium diboride, molybdenum disilicide) were rejected due to oxidation sensitivity at temperature or excessive thermal expansion compared to the thermal expansion coefficient to the AlN films.

Where metal properties can generally be specified in terms of alloy content and heat treat, ceramics such as $\mathrm{SiC}$ are much more complex. Material properties such as conductivity vary based on processing method and the specific process used. For example, reaction bonded $\mathrm{SiC}$ actually contains a substantial amount of elemental metallic silicon, which affects the properties. SiC made by CVD is purer, more expensive, and available in more limited forms. In the second year of the program, several different grades of $\mathrm{SiC}$ were investigated with reasonable results. The electrical conductivity issues with $\mathrm{SiC}$ have been overcome, but the AlN films are still not durable under thermal cycling. Deposition also was successful on a novel, electrically conductive grade of sintered aluminum nitride. Titanium silicocarbide looked promising from a machinability standpoint, but its relatively high coefficient of thermal expansion is too high to be compatible with the AlN films. Porous tungsten carbide appeared to have promise, as the 
porosity would improve the acoustic impedance match with AlN while attenuating substrate echoes, but was not obtainable commercially. The AlN did not adhere to a cobalt-coated SiC substrate; WC coatings were too rough and thin to be used as a base for deposition.

Finally, a different division of Saint-Gobain from the one that produces the Hexoloy $\mathrm{SiC}$ material agreed to team with UDRI to further investigate coating $\mathrm{SiC}$ with AlN. They provided siliconized $\mathrm{SiC}$ and porous $\mathrm{SiC}$ substrates, analysis of the interface chemistry, and suggestions for surface treatments.

Subtask 1C: Experimentally explore the feasibility of AIN deposition onto identified new substrate materials such as graphite, alumina graphite, silicon carbide, titanium diboride, and molybdenum disilicide. January 2003-May 2005.

Deposition was extended from tungsten carbide substrates to commercially pure (Grade 2) titanium, various grades of silicon carbide, and a bulk aluminum nitride. For elevated temperature use, only the WC appears practical at this writing, although similar crystal structures and thermal expansion suggest that $\mathrm{SiC}$ substrates should bond adequately with the AlN. While the films on $\mathrm{SiC}$ appeared good initially and produced adequate ultrasonic signals, they failed to withstand temperature cycling. Microscopic analysis showed that even before cycling, substantial defects were present in the films that likely caused their failure upon heating.

WC can be used beyond $1000^{\circ} \mathrm{C}$ if the sensor is constructed to exclude oxygen; the AlN films will likely also benefit at temperatures above $800^{\circ} \mathrm{C}$.

Subtask 1D: Investigate the feasibility of using pulsed laser deposition of the AIN films onto substrates. The substrate pressure and temperature will be varied to determine conditions conducive to producing films specific for this high temperature sensor application. January 2003-January 2004.

Three very small AlN films were produced on SiC substrates using the PLD method. The useful area of these films is likely too small for use in a full scale sensor, and difficulties were encountered in evaluating these films ultrasonically. However, it is possible that this process might prove useful for "repairing" CVD films with pinhole or other defects.

\section{Piezoelectric AIN Film Evaluation}

Task Description: An evaluation of films deposited in task 1 will be completed in task 2. The films and high temperature substrates will be characterized structurally and ultrasonically. Characterization of the films will include the adhesion, oxidation, and continuity of the films when exposed to both room temperature and high temperature atmosphere. The ultrasonic properties of the films will also be determined by investigating the frequency, bandwidth, and signal strength at elevated temperatures. Using a scanning electron microscope with $X$-ray diffraction the surface and subsurface of the films will be analyzed to provide data on the crystal structure, defects, and bonding. 
Subtask 2A: Characterize films by examining the thermal and physical properties of the films. Structural evaluation includes adhesion, oxidation, and continuity of the films as a function of time, temperatures up to $1000^{\circ} \mathrm{C}$, and exposure to physical damage. December 2002- June 2005.

The films on titanium were found to be inferior upon heating above $100^{\circ} \mathrm{C}$ and not durable enough for deployment in a sensor. Heating causes films on titanium to disbond from the surface of the substrate, rendering them useless as transducers. Surface roughening and additional cleaning to promote adhesion was ineffective. Most likely, the mismatch in thermal expansion between the titanium and AIN causes large stresses at the interface, breaking the bonds formed during deposition. While disbonded films on WC actually pulled away a small amount of the substrate material when they failed, the opposite effect was observed on the titanium: there was often a thin coating remaining on the titanium when the film disbonded. The poor results of titanium substrates pointed away from using other materials with a large expansion mismatch with the AlN, and toward lower expansion substrate materials.

The requirement for a low expansion material suggests ceramic materials, but electrically conductive ceramics are uncommon. One exception, silicon carbide, can be doped to be conductive and it was tried next. The acoustic impedance of $\mathrm{SiC}$ is close to that of AlN, allowing an AlN film on a $\mathrm{SiC}$ substrate to produce a high bandwidth ultrasonic transducer with very little ringing of the ultrasonic pulse. A preliminary evaluation of films on $\mathrm{SiC}$ was positive, with films remaining adhered through polishing and one film cycled to $400^{\circ} \mathrm{C}$ and back to room temperature with no ill effects. Ultrasonic data was not collected from these films, possibly due to the "low resistivity" of the chosen grade of $\mathrm{SiC}$ not being low enough. As discussed in the Experimental section, film adhesion to $\mathrm{SiC}$ appeared to be good initially, but thermal damage accumulated easily, in some cases as badly as with titanium substrates. The best initial results were with the sintered material; the AlN seemed to form a weaker bond with the CVD material, even though it should have been more pure. This pointed towards mechanical bonding with the very different microstructure of the sintered material, which led to the investigation of porous and siliconized $\mathrm{SiC}$ substrates during the third year of research. Film behavior was found to be similar to that of the better films on monolithic SiC. The film integrity was compromised by exposure to high temperatures.

Subtask 2B: Characterize films by evaluating the ultrasonic properties of the films and substrates. Ultrasonic evaluation includes frequency, bandwidth, and signal strength at ambient and elevated temperatures. December 2002- June 2005.

New films on tungsten carbide show signal strength and properties similar to previously produced films. Films thick enough to have center frequencies below $30 \mathrm{MHz}$ and substantial energy below $10 \mathrm{MHz}$ are routinely produced. Films on titanium have similar ultrasonic properties with respect to center frequency and signal strength. Because the titanium is a closer acoustic impedance match to the AlN than the tungsten carbide substrates, the ultrasonic pulse shape is improved on the titanium, having a more broadband signal with less resonant ringing. Ultrasonic data from AlN films on titanium and tungsten carbide is shown in Figures 34-37. 


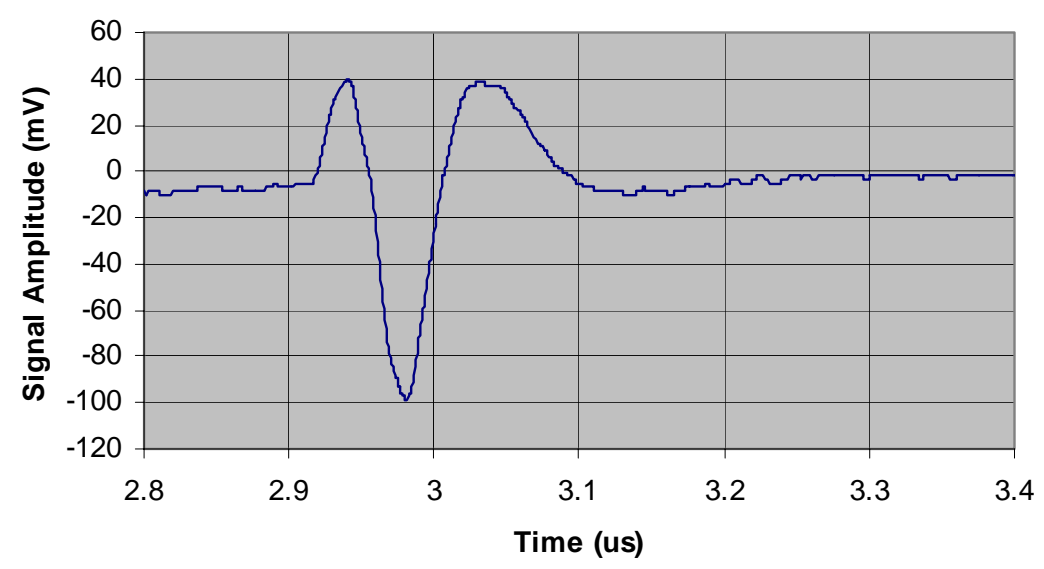

Figure 34. First back-surface echo of ultrasonic pulse from $\sim 13 \mathrm{MHz}$ AlN film on WC.

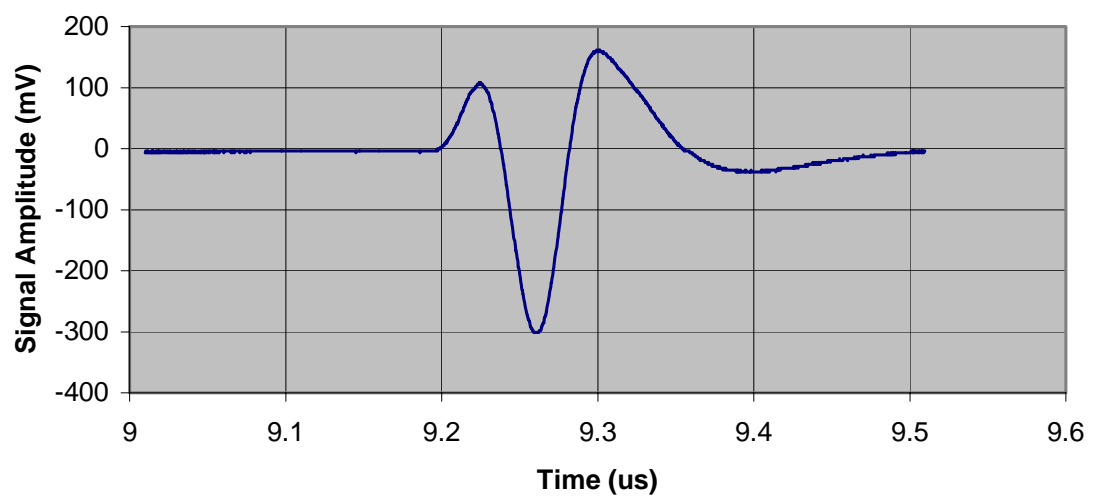

Figure 35. First echo in steel test block of ultrasonic pulse from $\sim 13 \mathrm{MHz}$ AlN film on WC.

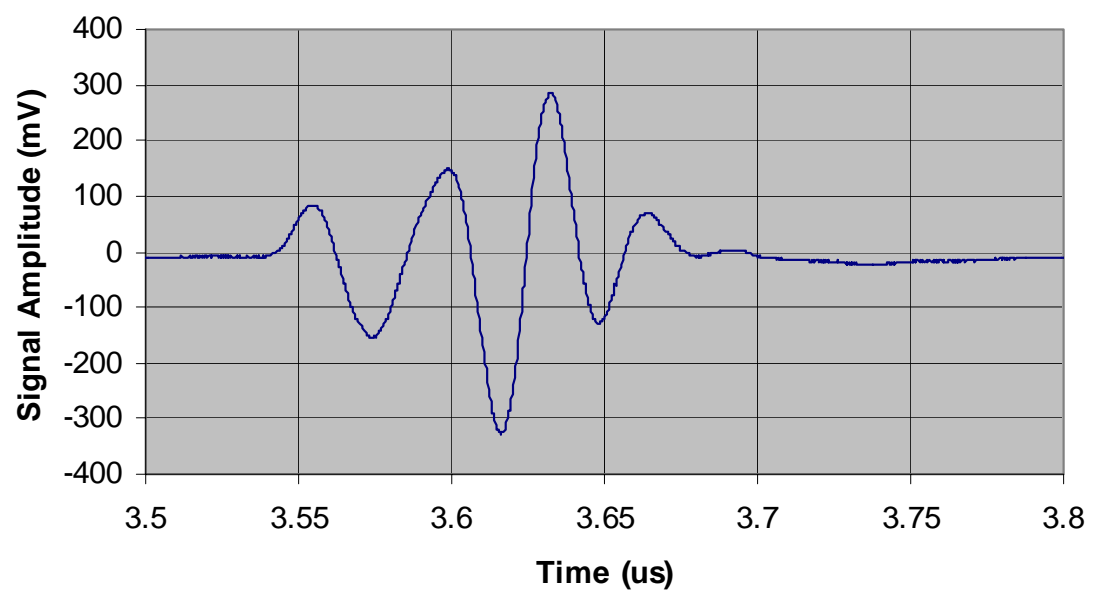

Figure 36. First back-surface echo of ultrasonic pulse from $\sim 30 \mathrm{MHz}$ AlN film on titanium. 


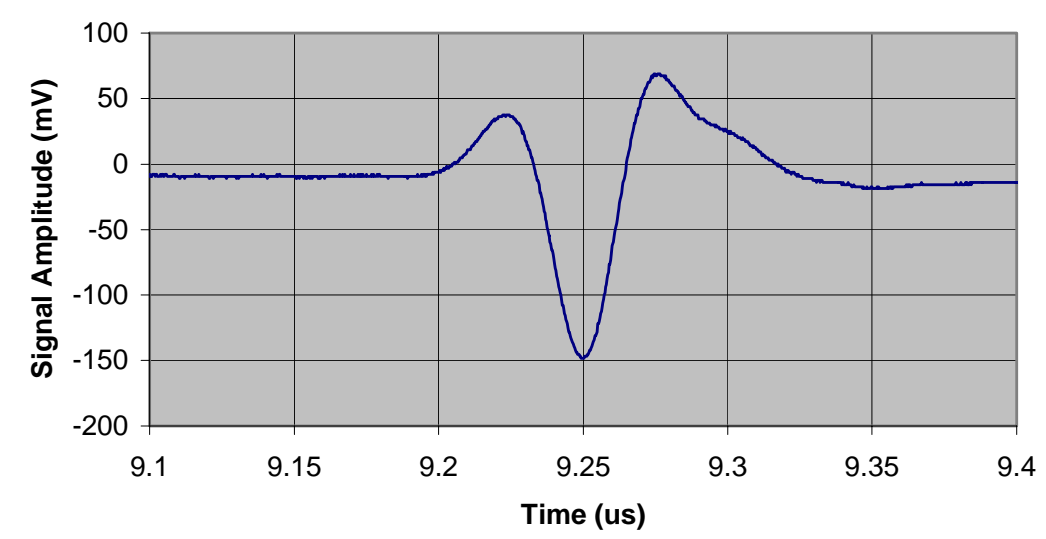

Figure 37. First echo in steel test block of ultrasonic pulse from $\sim 30 \mathrm{MHz}$ AlN film on titanium, with higher frequencies filtered out by test block

The new AlN films on $\mathrm{SiC}$ possess ultrasonic properties similar to previous films on tungsten carbide and titanium. Films thick enough to have center frequencies below $30 \mathrm{MHz}$ and substantial energy below $10 \mathrm{MHz}$ were produced. The acoustic impedance of $\mathrm{SiC}$ is even a better match for AlN than that of titanium, and the resulting films have a very desirable wide bandwidth with minimal ringing. Early problems with making adequate electrical connections to the $\mathrm{SiC}$ substrates have been overcome to facilitate this testing.

Figures 38 and 39 show strong signals from an AlN film on SiC. The signal in Figure 38 is the second reflection of the sound from the back surface of the SiC substrate. Substrate echoes are only moderately useful to evaluate signal strength, but may be used to evaluate bandwidth and center frequency. This film has a $-6 \mathrm{~dB}$ bandwidth of $75 \%$ and a center frequency of $32 \mathrm{MHz}$, as

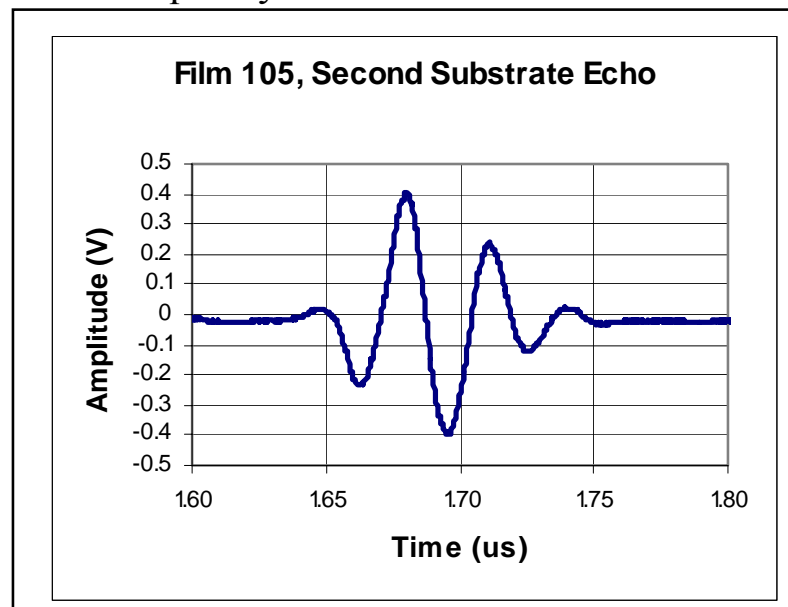

Figure 38. Wideband ultrasonic signal produced by AlN film on SiC substrate.

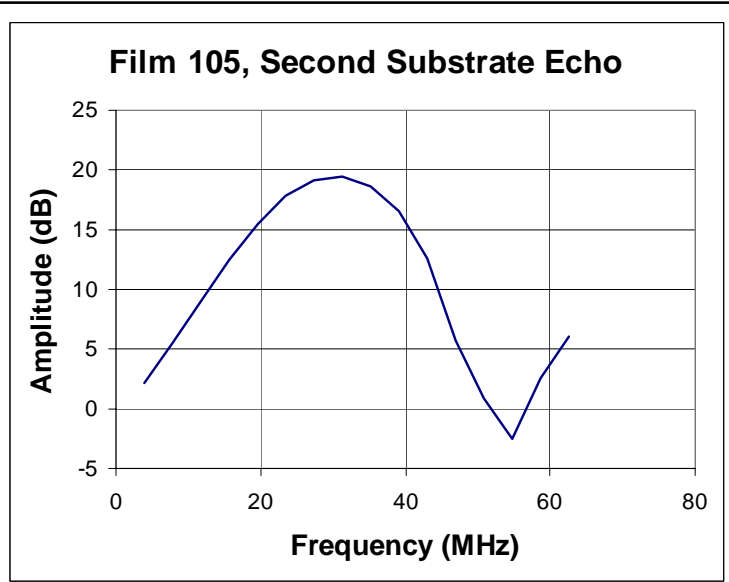

Figure 39. Frequency spectrum of ultrasonic signal in Figure 38.

shown in Figure 39. Figure 40 shows a reflection of a pulse from the same film off an external, $25 \mathrm{~mm}$ thick block of 17-4 PH stainless steel. This block has polished, parallel faces, so the amplitude of the echo in it may be used to compare the strength of films to one another. The signal in Figure 39 is $\sim 350 \mathrm{mV}$ p-p, $15 \mathrm{MHz}$ center frequency, and was recorded with only $20 \mathrm{~dB}$ of gain with a $200 \mathrm{~V}$ excitation pulse. These waveforms are representative of the signals produced by the stronger AlN films on $\mathrm{SiC}$. The reason for the change in center frequency is 
that the test block material acts like a low pass filter, attenuating the higher frequency components of the signal, which is also attested to by the reduced amplitude in Figure 39. The high bandwidth of the films on $\mathrm{SiC}$ spreads the ultrasonic energy to lower and higher frequencies, producing more energy likely to get through attenuative realworld materials.

The new AlN films on porous SiC possessed ultrasonic properties similar to previous films on tungsten carbide and titanium. The acoustic impedance of the porous $\mathrm{SiC}$ matched the AlN much like the monolithic

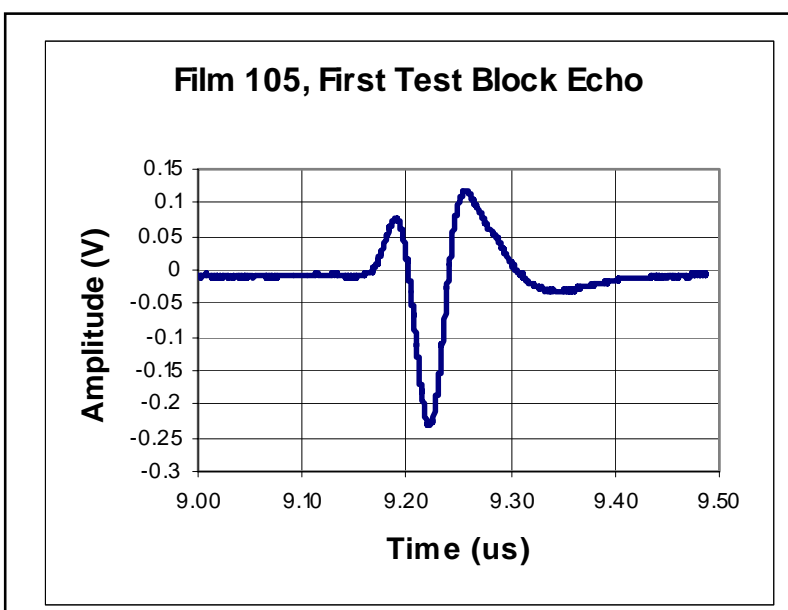

Figure 40. The same signal, reflected through a $25 \mathrm{~mm}$ test block. $\mathrm{SiC}$, producing wide bandwidth ultrasonic pulses. The acoustic attenuation of the porous $\mathrm{SiC}$ was good, returning only about $25 \%$ of the energy as solid or siliconized SiC when interrogated by a commercial $10 \mathrm{MHz}$ transducer. Attenuation and scattering is likely to be greater at higher frequencies.

Subtask 2C: Characterize films using x-ray diffraction and scanning electron microscopy to examine the piezoelectric crystal structure, defects, bonding difficulties, and other material issues. March 2002-December 2004.

Electron dispersion spectroscopy (EDS) techniques have proven useful along with electron microscopy to characterize the nature of the film delaminations caused by thermal cycling. As noted above, indications are that a clean separation occurs between the $\mathrm{AlN}$ and the $\mathrm{SiC}$ in most failures, indicating a bond that is primarily mechanical in nature.

Earlier analysis indicated that disbonds on monolithic SiC were failing cleanly at the AlN-SiC interface. Additional work with the porous substrates revealed the presence of two separate AlN layers. Oxides were discovered on the surfaces where coating failure occurred. Typical results from these analyses are presented above. One additional note is that the as-deposited AlN films exhibit some porosity and through-thickness defects on the microscopic scale.

Subtask 2D: Relate substrate surface preparation to film quality (adhesion, defective areas, film thickness uniformity, and orientation of the piezoelectric crystals). December 2002December 2004.

Various surface preparation methods were used on titanium substrates, eventually allowing adhesion at room temperature, but not robust enough to overcome the thermal expansion mismatch. Much as with WC, simple polishing to expose a uniform, slightly rough surface appeared to be optimal. Minimal surface preparation of silicon carbide substrates was also required, with good films resulting from no preparation or from polishing and cleaning the asreceived substrate material. Oxidation of the $\mathrm{SiC}$ may be an issue, with the presence of an oxide layer at the surface prior to deposition of the AlN not optimal; however, adhesion did not appear 
to suffer on oxidized substrates in our tests. No relationship has been discovered to date between surface condition and "good" and "bad" areas of a film. Surface preparation also does not appear to have a significant effect on crystal orientation in the films.

\section{High Temperature Coupling}

Task Description: A literature survey will be made of methods to conduct ultrasonic coupling at elevated temperatures and those that are most suited to equipment health monitoring. Those methods that appear most suited for the application will be verified in the laboratory, in particular, the effect of the coupling layer on the impedance matching will be examined.

\section{Subtask 3A Perform literature survey re: high temperature coupling. January 2003-August 2003.}

A literature survey was completed by UDRI with the help of a mechanical engineering student employed as part of our cooperative education program. Commercial products and a variety of historical coupling methods were identified, including molten glasses, ceramic adhesives, and metal foils. The data gathered was evaluated and two of the most promising methods for use with AlN transducers were be selected for experimental testing.

A coupling material is required to transmit ultrasonic energy from the transducer into the test object, displacing air between the transducer and the surface of the test object that would cause the sound energy to be reflected. The reflection of sound energy is caused by a mismatch in the compressibility of two materials, as measured by the acoustic impedance. Air has a dramatically lower impedance than solids or liquids, and the higher the degree of an impedance mismatch the more sound is reflected. Therefore, only a very small fraction of the ultrasonic energy from the transducer is transmitted to the test object, and a similar percentage of the returning sound energy is not received by the transducer.

To reduce this signal attenuation many different methods and couplants have been employed. At room temperature, typical couplants include water, glycerin, elastomers and various kinds of specially produced gel. At high temperatures the number of available couplants rapidly decreases. Specially produced commercial couplants can only reach a temperature of $590^{\circ} \mathrm{C}$. However, some applications require temperatures exceeding $800^{\circ} \mathrm{C}$.

Several methods for coupling ultrasound at very high temperatures have been attempted. The first and possibly the least plausible is the Newton's rings method. This method entails polishing mating surfaces flat and parallel such that the air gap between them is reduced below $0.01 \mu \mathrm{m}$. Newton's rings optical method would then be used to evaluate the flatness of the surfaces. However, even with an air gap of $0.001 \mu \mathrm{m}$. only ultrasonic energy with frequencies less than 5 $\mathrm{MHz}$ would be transmitted.

More conceivable is the use of a liquid or solid couplant. Metal foils such as zinc are sometimes used for couplant at lower temperatures. However, at the $800-1000^{\circ} \mathrm{C}$ temperatures required for this research, zinc would easily melt, flow away, and oxidize. A metal with a much higher melting temperature than $800^{\circ} \mathrm{C}$ would be much more effective. Platinum, for instance, is often 
used up to $1000^{\circ} \mathrm{C}$, making it an excellent candidate for a couplant. If thin foils were used in small areas, especially for semi-permanent transducer installations, the expense of platinum would be offset by the very small quantities required.

Another solution to this problem is most likely a form of glass. Research has turned up an article stating that coupling temperatures nearing 800 degrees Celsius had been reached by using a form of glass solder. Glass, unlike liquid metals, is able to adhere to both surfaces, preventing air pockets from blocking the transmission of ultrasound. However, there are an exceedingly high number of chemical compositions for various glasses and thus a great deal of research must be done into what would allow for the best sound transmission and chemical compatibility. An additional unknown is if the molten glass layer is thin enough to have a minimal effect on the strength of the electric field through the thickness of the AlN film.

Metal foils (aluminum, silver, gold, platinum) and molten glasses were selected as the methods with the highest probability of success and were further evaluated experimentally.

\section{Subtask 3B Design high temperature apparatus for testing films and coupling to test objects. August 2003-December 2003.}

Based on the literature survey, the technical community appeared to have had limited success in developing ultrasonic coupling methods suitable for use at high temperatures. Accordingly, this subtask was expanded through the second year of the program, and formed the basis of an undergraduate Honors Thesis for the student who performed the literature survey. A simple test fixture was designed and constructed as described in the Experimental section and shown in Figure 25. Tests were performed on metal foil coupling, beginning with aluminum and progressing to silver and gold, with gold chosen as optimum due to its oxidation resistance and melting point above $1000^{\circ} \mathrm{C}$.

Figures 41-44 compare the first echo in the test block using a commercial water-based couplant at room temperature to the echoes received using the various foil couplants at elevated temperatures. Note that good coupling is achieved, even at temperatures approaching the melting point of the aluminum foil. Aluminum and silver foils showed some degradation with time, likely the result of oxidation. The strongest signals were achieved using the gold foil. In general, some degree of coupling occurred as soon as a compressive load was applied to the test fixture. Upon heating, the softening of the foils improved the coupling, and a high degree of coupling was maintained even after cooling and the removal of almost all the compressive load. A single AlN film on a tungsten carbide substrate was used for all the foil couplant tests in order to insure that the signal being coupled was of consistent strength. 


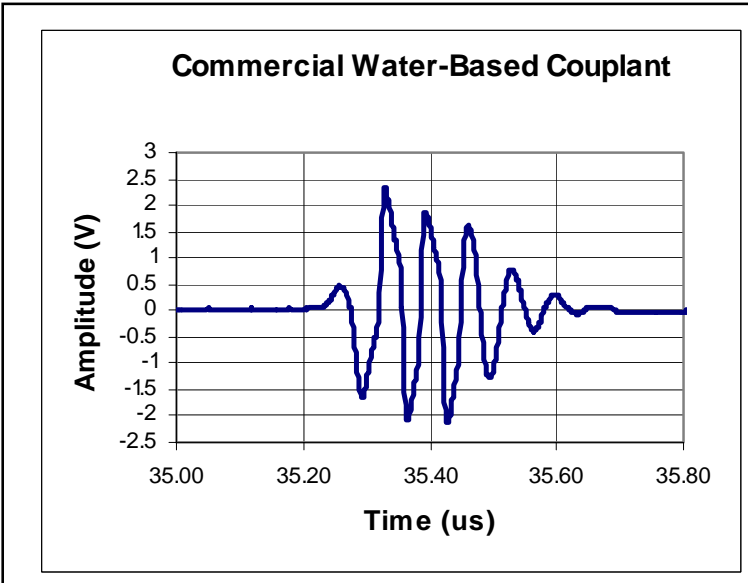

Figure 41. First reflection in $100 \mathrm{~mm}$ test block, water-based couplant, room temperature.

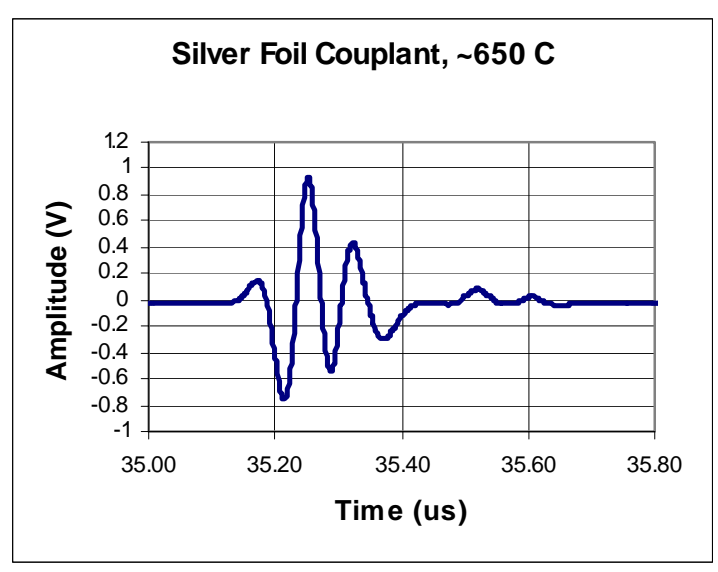

Figure 43. First reflection in $100 \mathrm{~mm}$ test block, silver couplant.

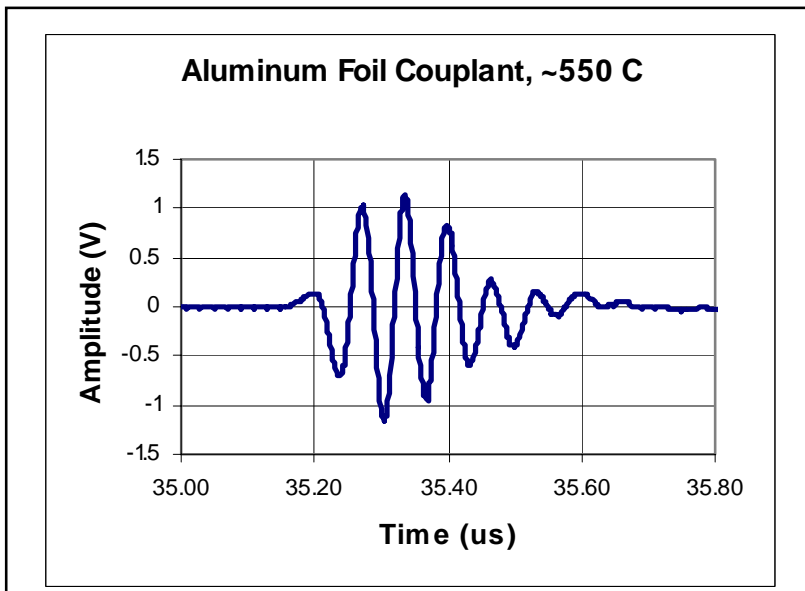

Figure 42. First reflection in $100 \mathrm{~mm}$ test block, aluminum couplant.

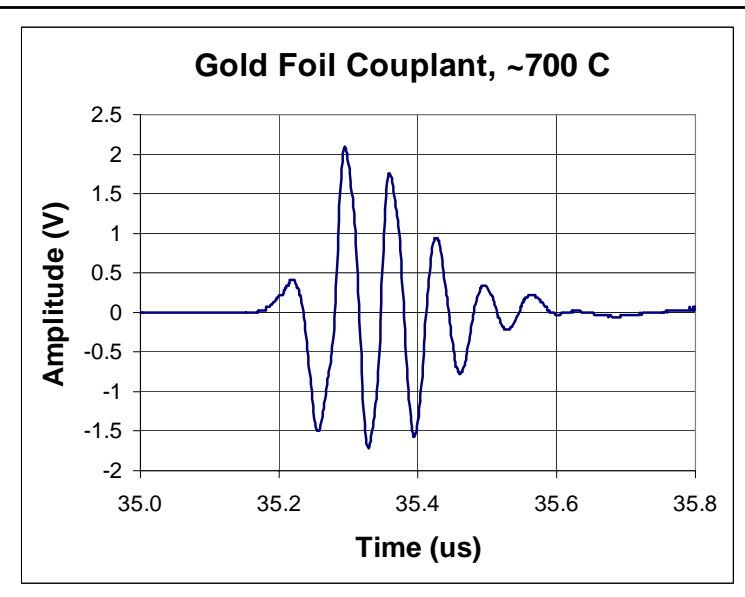

Figure 44. First reflection in $100 \mathrm{~mm}$ test block, gold foil couplant.

The aluminum foil couplant was used to evaluate the effects of compressive load on coupling effectiveness for foil couplants. Figure 45 shows an increase in coupling effectiveness with load up to about $15 \mathrm{kN}$, corresponding to a pressure of about $10 \mathrm{MPa}$. Note that this value cannot be compared to the yield strength of the aluminum because creep effects dominate at these temperatures and the thin aluminum layer is in a triaxial state of stress, corresponding more closely to a hydrostatic pressure than uniaxial compression. This shows that for foil coupling, there is an ideal load that should be reached, beyond which additional loading is unnecessary. As mentioned earlier, this load need not be maintained after initial loading and heating.

Aluminum foil couplant was also used to evaluate the effects of temperature on coupling effectiveness for foil couplants. The summary data in Figure 46 show a weak dependence on temperature compared to the dependence on compressive load. Good coupling was achieved at $12 \mathrm{kN}$ essentially independent of changes in temperature. At the lower load levels, increasing the test temperature to between $500^{\circ} \mathrm{C}$ and $550^{\circ} \mathrm{C}$ improved the coupling, although further increases may be detrimental. The best route for coupling a transducer appears to be applying adequate load and heating to within a specified softening range. 
Gold leaf was found to perform as well or better than the gold foil, comparing favorably with the coupling achieved by a commercial water-based couplant used at room temperature. Figure 47 shows that the initial coupling with the gold leaf is weak, but as the temperature increases, the thin gold leaf quickly conforms to any irregularities at the interface and good coupling is obtained. Coupling is maintained even after cooling the test fixture to room temperature.

Figure 48 shows ultrasonic waveforms with water-based and gold leaf coupling. In addition to operating at high temperatures, the gold leaf appears to better pass the high frequency components of the pulse. The signal through the leaf exhibits ringing initially, but once the gold softens and coupling is achieved, this ringing disappears and a more broadband pulse suitable for testing is obtained. The conclusion is that the gold leaf appears to be an optimal solution to the high temperature coupling problem, if a moderate amount of pressure can be applied.

Testing was also performed using molten glass couplant. Figure 49 shows the glass powder (white) in the test fixture prior to heating; Figure 50 shows it on the AIN film after the test was completed. The AlN film was separated from the test block while the glass was still soft. The ultrasonic coupling within the appropriate temperature range was adequate, as shown in Figure 51, although this data was acquired at $10 \mathrm{~dB}$ greater gain and still has a lower amplitude than the earlier plots. The molten glass was found to be effective in only a narrow temperature range for

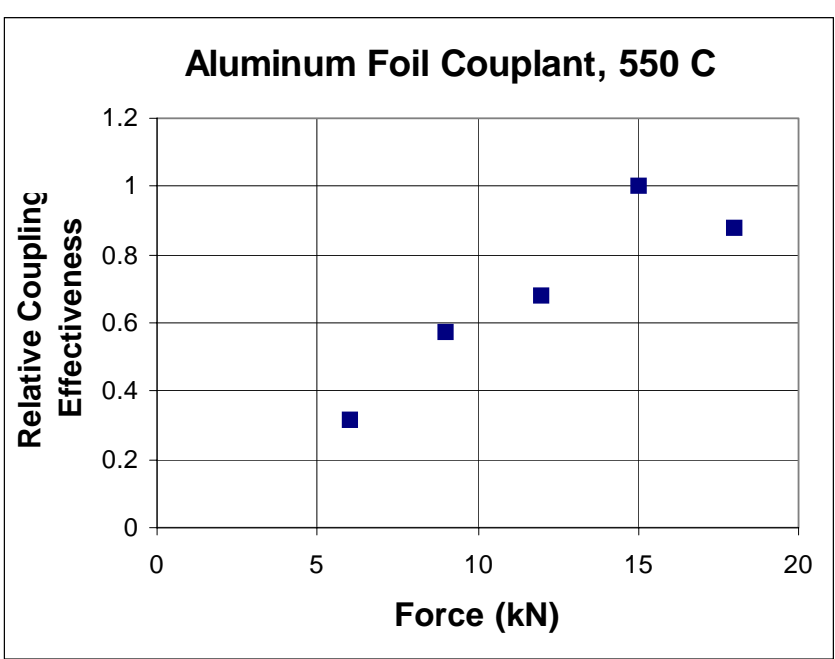

Figure 45. Coupling effectiveness as a function of compressive load.

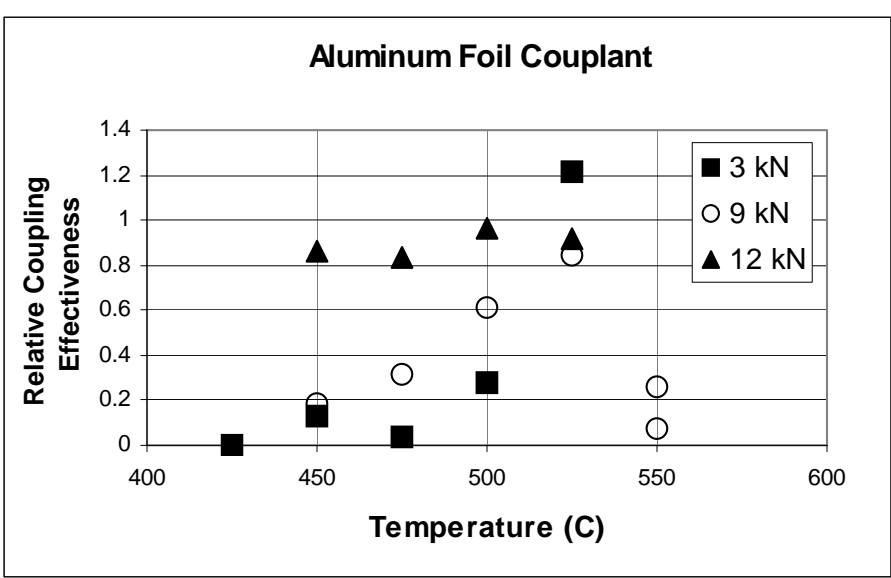

Figure 46. Coupling effectiveness as a function of compressive load and test temperature.

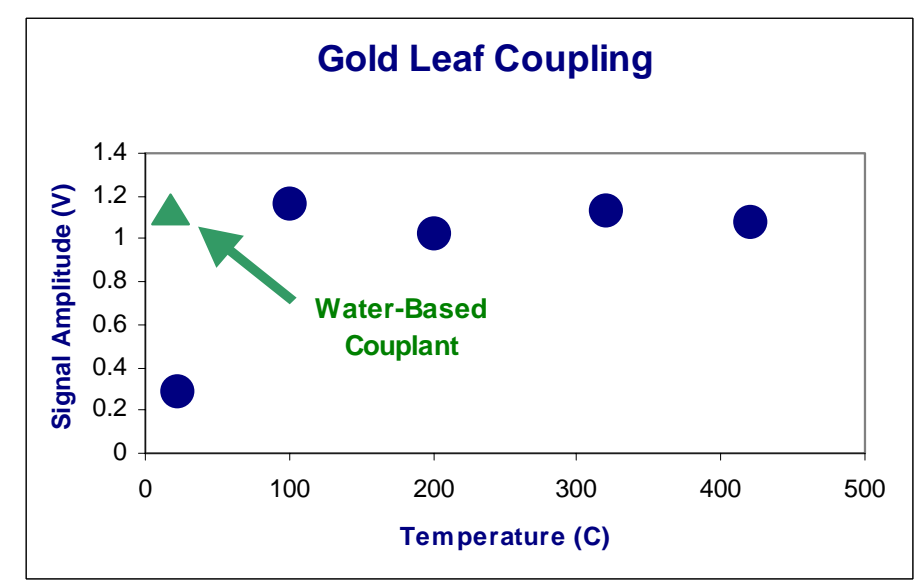

Figure 47. Gold leaf coupling compared to water-based couplant. 
the two glass compositions tried. Below this temperature, the glass layer did not soften and thin, preventing ultrasonic coupling and reducing the electrical field strength driving the piezoelectric film. At much higher temperatures, the glass began to react chemically with the air and with the steel test block. Figure 52 shows the same setup, 30 minutes later, with the temperature slowly increased. The signal strength is greatly diminished. Molten glass appears to be an effective couplant for limited use, but the metal foil method does not

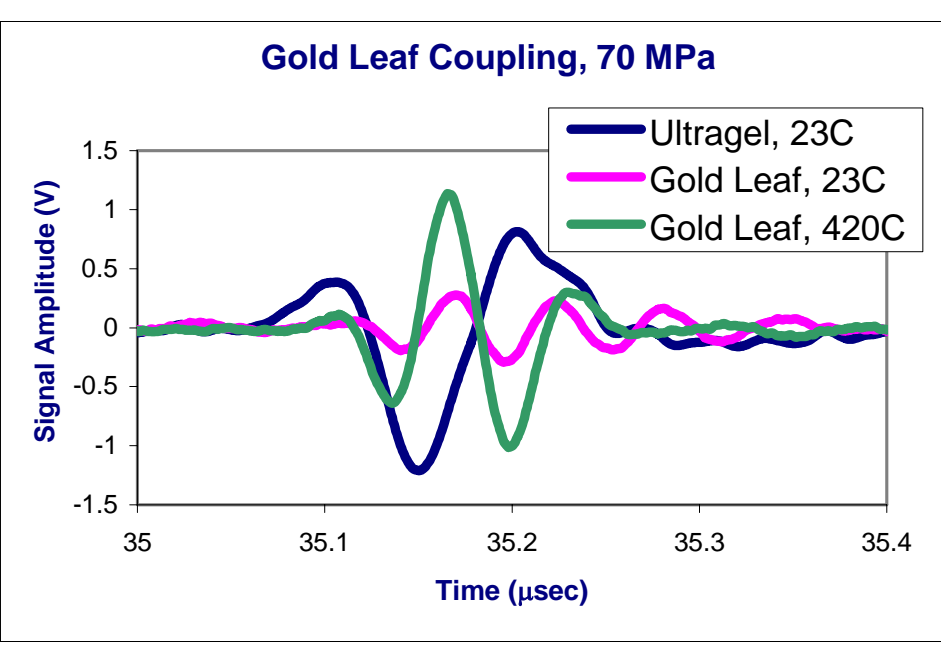

Figure 48. Ultrasonic signals using gold leaf coupling, compared to using water-based couplant. suffer from material incompatibility issues, has a wide operating range, and was selected as the optimum couplant for use in the program.

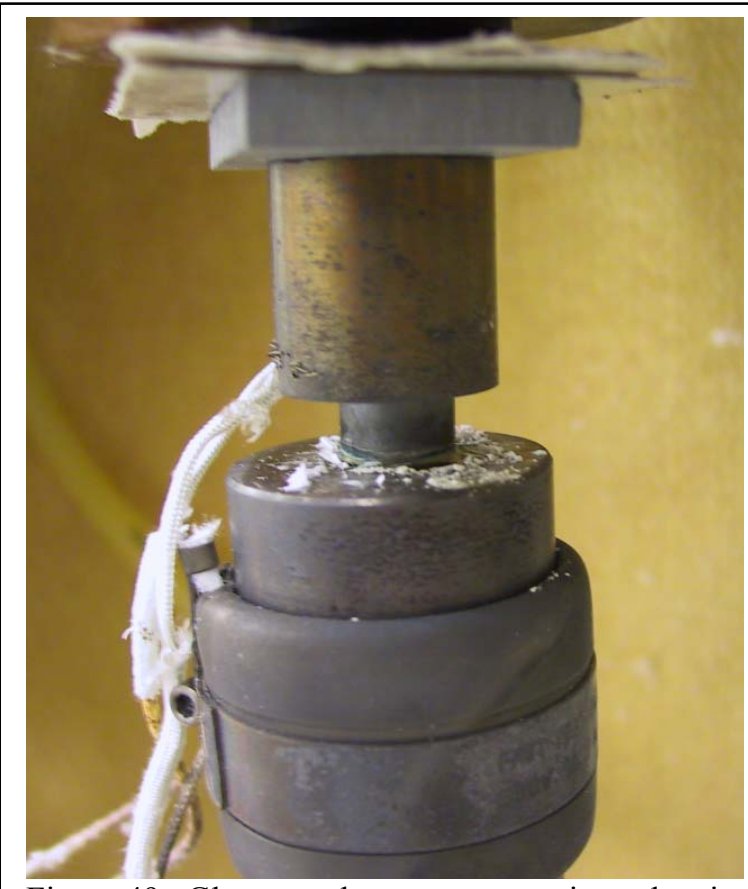

Figure 49. Glass couplant test setup prior to heating.

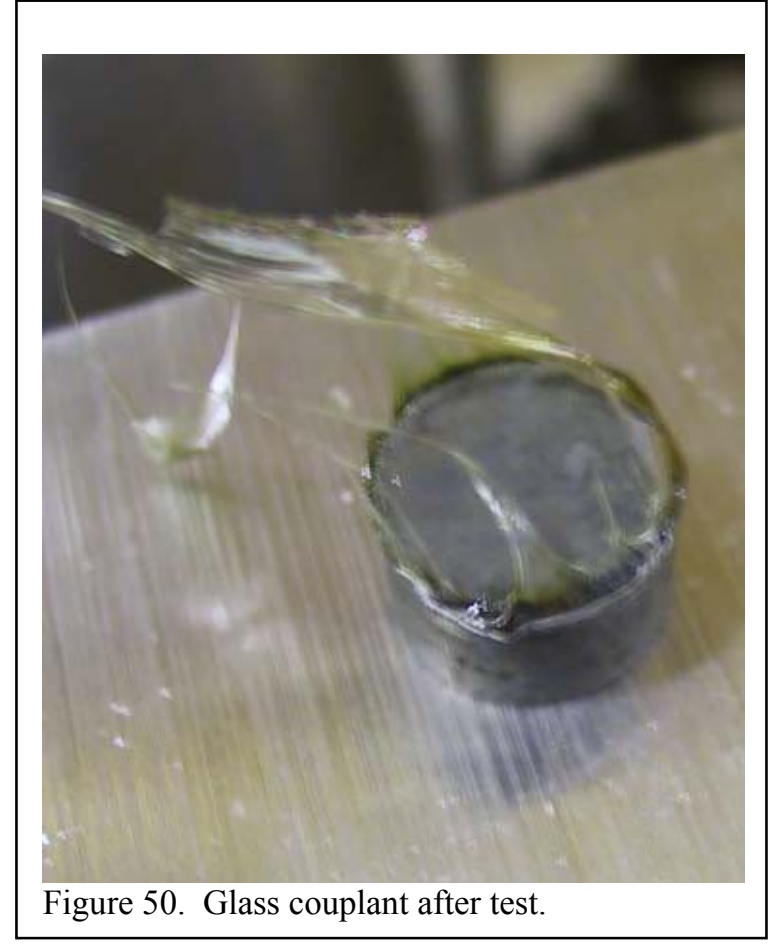




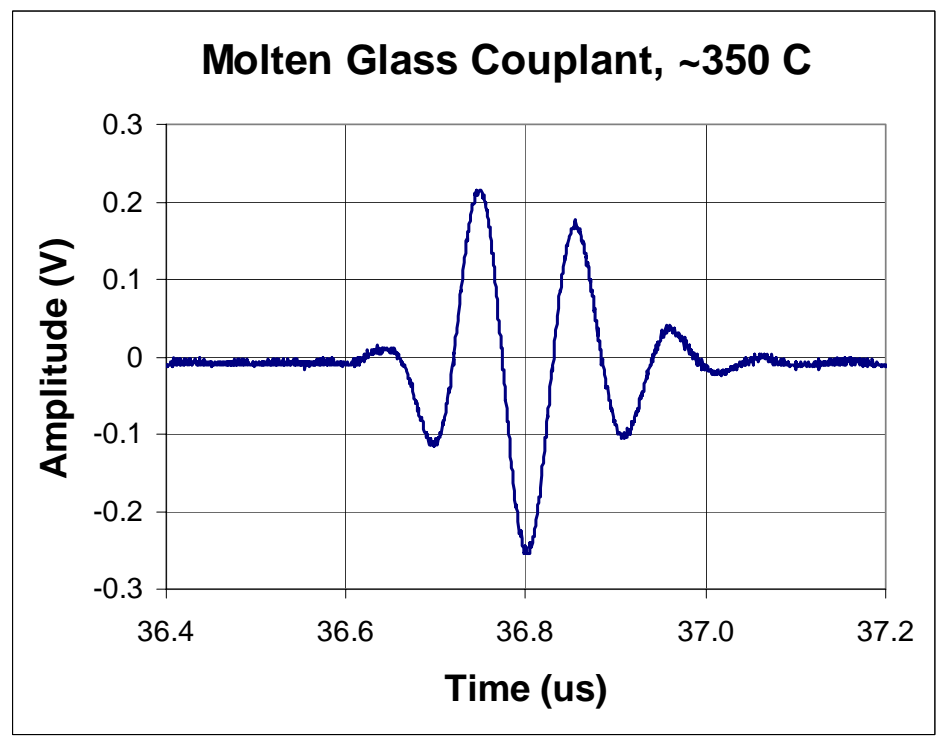

Figure 51. Glass-coupled ultrasonic signal.

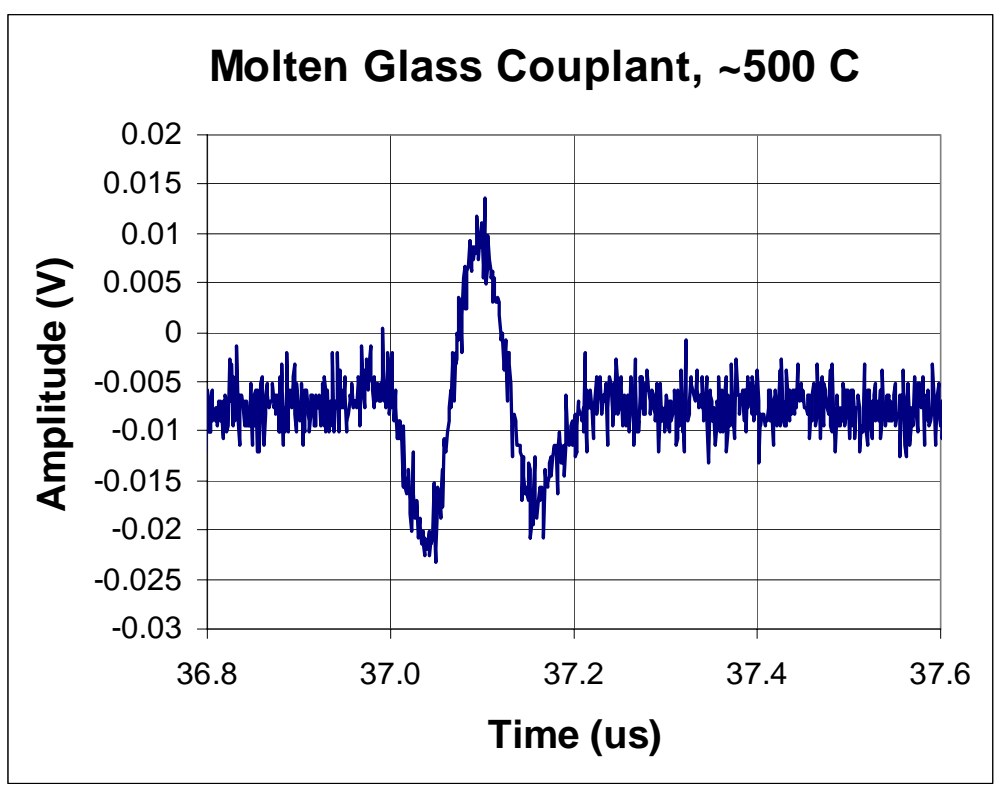

Figure 52. Glass-coupled ultrasonic signal. 


\section{Equipment Health Monitoring Demonstration}

Task Description: A specific application of an ultrasonic piezoelectric sensor for monitoring equipment health will be selected. Requirements for the specific application will be defined and used to direct the design and fabrication of the sensor. The sensor design will focus on the AIN film, electroding, ultrasonic coupling, high temperature wiring. The feasibility of the sensor will be demonstrated in the laboratory under conditions that simulate the specific application.

Subtask 4A Identify specific application to test AIN film based ultrasonic sensor. Application must be able to be mimicked in the laboratory to demonstrated feasibility of sensor. May 2003-May 2004.

Three candidate applications were originally identified. The first is as a point sensor to monitor the thinning of the inner layer of refractory in a coal gasifier. A sample of a typical gasifier hot face refractory, Zirchrom 90, was obtained from Saint Gobain Ceramics. A commercial $10 \mathrm{MHz}$ contact ultrasonic transducer was used to investigate the ultrasonic properties of the refractory, but no transmission of sound was achieved. Refractory monitoring was discontinued as a candidate application for the ultrasonic sensor. It is possible that much lower frequency $(<1$ $\mathrm{MHz}$ ) ultrasound or an impact-echo method might be appropriate to investigate in the future.

A second candidate application was to monitor the condition of a thermal barrier coating applied to a metal part. A point sensor installed in a critical area would be able to detect delamination of the thermal barrier; guided waves could be used along a component to look for cracking. Likely the sensor would need to be miniaturized to be useful in this application.

The third candidate application was to monitor a piece of process equipment such as a heat exchanger. Ultrasonic inspection is commonly performed on such equipment during plant shutdowns. Welds and corrosion-sensitive areas are often trouble sources exhibiting wall thinning or cracking. High temperature transducers could be permanently mounted at critical locations and interrogated periodically. A single ultrasonic instrument could be multiplexed to any number of sensors for continuous, automatic monitoring.

Given the inability to produce usable AlN films for a sensor, the selection of an application was delayed several times during the program, and finally transformed into a demonstration test using an LGS crystal to monitor the thickness of a test piece of metal, in a furnace environment, with a target temperature of $1000^{\circ} \mathrm{C}$.

Subtask 4B Set up laboratory for feasibility demonstration. May 2004- December 2004. Setup for the above test involved a simple assembly of a Satec SF-16 tube furnace, 2 BarberColman 560 furnace controllers, The Utex 340 pulser-receiver, and an Agilent 54622A oscilloscope. Thermocoax high temperature sheathed cable was used to transmit the signal out of the hot zone. 
Subtask 4C Design and fabricate sensor specific to the application including the AIN film, electroding, ultrasonic coupling, and high temperature wiring. May 2004-June 2005.

Transducer design work began in the second year of this project. Metal-sheathed thermocouples and coaxial cable were obtained to evaluate for transmission of the ultrasonic signals from the hot transducer back to signal-conditioning electronics. A standard laboratory pulser-receiver was used for the majority of testing. Electrical connections are made by spot welding where metalto-metal is possible, and creating conductive gold traces, like those on PC boards, across nonconductive materials. The materials for these traces, Hanovia Liquid Bright Gold "N" and AGSTM - Accent Gold for Silver were obtained from the art/ pottery industries. Liquid bright gold is used to put gold traces on pottery; AGS is a clay-like material used to make jewelry. Both materials, when fired, leave pure metallic gold.

The transducer design was set up to include metal-foil coupling directly to a test object and backing material. The gold leaf acts both as a couplant and an electrode on the piezoelectric crystal. For a self-contained transducer, a means of applying pressure to the couplant is required, essentially a stiff spring which will maintain a preload as differential thermal expansion occurs between different materials inside the transducer. UDRI has used a rhenium disk for this in vacuum, but long-term creep relaxation is an issue. Investigation led to two recently developed possibilities, both ceramic. Machined coil springs have been made from toughened zirconia which can be designed for the necessary loads, deflections, and temperatures. In addition, NHK Spring makes silicon nitride coil springs which have been tested to $1200^{\circ} \mathrm{C}$. Both of these are highly specialized, semi-custom items. Alternately, an open transducer design was selected for this test, with the weight of a steel cylinder used to provide a compressive load.

Finally, a backing material was required to improve the ultrasonic pulse emitted from the transducer. The requirements for this material were similar to those for transducer substrates evaluated in the program, with the relaxed criteria that electrical conductivity is not required. Reexamination of various ceramics and metals determined that SiAlON was a good impedance match for the LGS. As with silicon carbide, properties of this material vary by supplier and processing. Kennametal KY1540 cutting tool insert material was tried first as it was readily available, and was found to be about a $10 \%$ mismatch. Two other samples of a technical grade SiAlON were obtained from Accuratus and Vesuvius McDaniel. These showed a 3-5\% mismatch, and the Accuratus material was selected for use in the testing. The SiAlON proved to be extremely difficult to cut, even with diamond tooling; machinability may dictate a switch to another material in a production transducer. One candidate would be a slightly porous alumina, which could be designed to have the desired qualities of impedance match, temperature survival, and ultrasonic attenuation.

Subtask 4D Evaluate performance of sensor system at elevated temperatures $\left(700-1000^{\circ} \mathrm{C}\right)$ in selected application. December 2004- August 2005.

The test transducer described above was installed in the Satec furnace and connected to the UTEX pulser-receiver with a short piece of RG-58 patch cable. Initial pulser settings were as follows: $300 \mathrm{~V}, 27 \mathrm{~ns}$ pulse, $40 \mathrm{~dB}$ gain, pulse-echo mode, $5 \mathrm{MHz}$ high pass filter, $60 \mathrm{MHz}$ low pass filter. The furnace was closed top and bottom to minimize convective heat loss and heating 
was begun. Data acquisition began at $150^{\circ} \mathrm{C}$, with a faint signal becoming visible, corresponding to resonant vibration of the LGS crystal, shown in Figure 53. This is the same vibration mode as in Figure 29, but with a poor signal to noise ratio.

Between $300^{\circ}$ and $400^{\circ}$, the signal improved markedly, likely due to the gold leaf softening and conforming to the crystal, effectively increasing the active area. Figure 54 shows the signals at this time. Note that the pulser-receiver gain had been turned down by $15 \mathrm{~dB}$ to $25 \mathrm{~dB}$, data was collected further out in time after many more reverberations, but that the amplitude and $\mathrm{S} / \mathrm{N}$ ratio were still better. Signal improvements continued in this fashion, peaking at $\sim 600^{\circ}$, similar to what was seen in Figure 30.

This behavior appears to be a combination of two effects. First, the increase in signal strength is likely due to a material property where the piezoelectric effect in the material is maximum around $600^{\circ}$ or a little higher. Second, the LGS material softens, becoming less stiff and exhibiting more damping at higher temperatures. Figure 55 shows this effect, with vibrations decaying more than twice as fast at $700^{\circ}$ as at $500^{\circ}$. Interestingly, this effect levels off at the higher temperatures, indicating that the decreasing signal amplitude is likely a material property of the LGS. However, the $\mathrm{S} / \mathrm{N}$ ratio does not worsen significantly as temperatures increase, as it is still quite good at $850^{\circ} \mathrm{C}$, shown in Figure 56.

These prove the applicability of the LGS crystal, but say nothing about using it to interrogate a structure. In this test, it appears that the pressure applied to the coupling foil was not sufficient to achieve ultrasonic coupling until very high temperatures, and then only minimally.

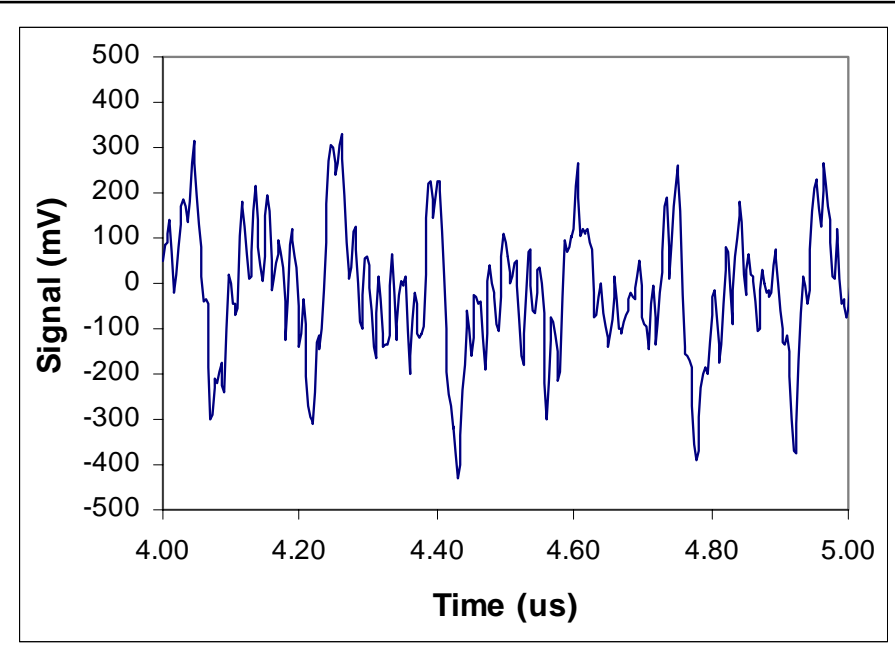

Figure 53. LGS crystal vibration at $150^{\circ} \mathrm{C}$

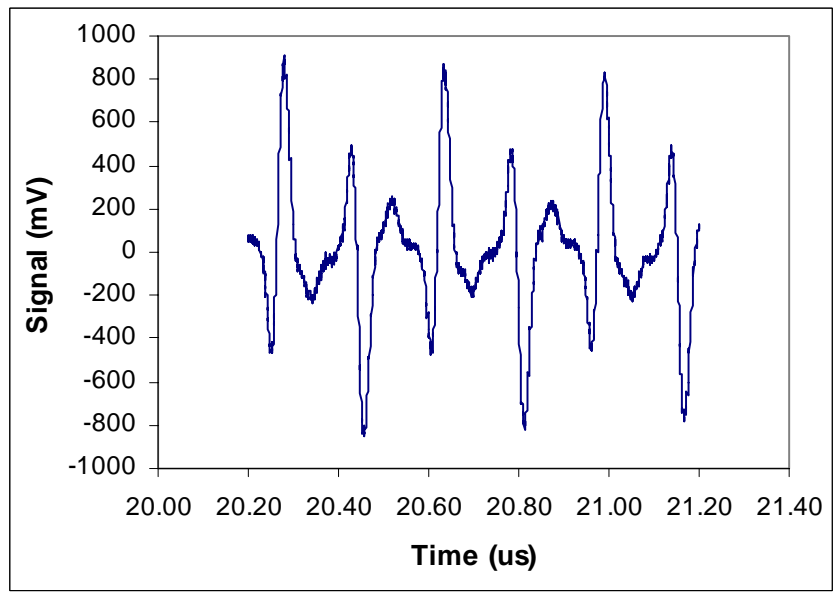

Figure 54. LGS crystal vibration at $450^{\circ} \mathrm{C}$

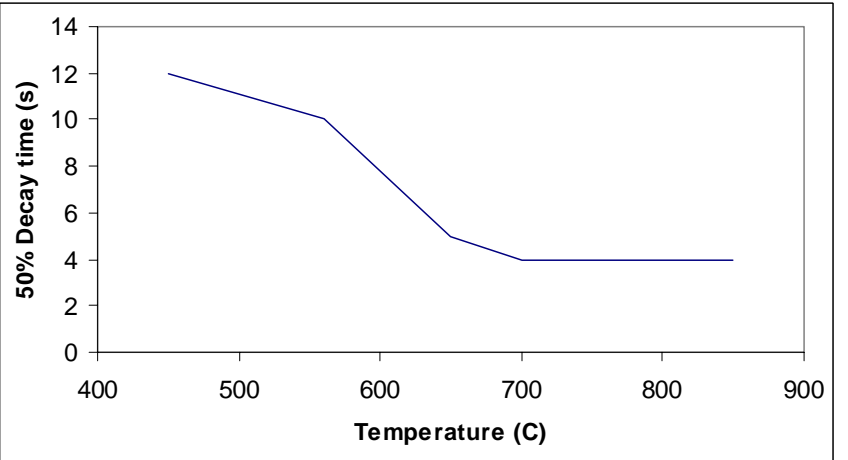

Figure 55. Increased damping with temperature 
Figure 57 shows the waveforms recorded from $800^{\circ}$ to $950^{\circ}$. At 800 , the signal is essentially still a uniform decay, but as the temperatures increase, a "notch" in amplitude can be seen at about 20 us. The increase in amplitude after this point is believed to be energy reflected back from the far end of the titanium block- the second echo of the initial oscillations, and occurs where it would be expected for the $26 \mathrm{~mm}$ titanium block. This signal is really too indistinct to be useful, but can easily be cleaned up in a next generation prototype sensor, which would also allow the resolution

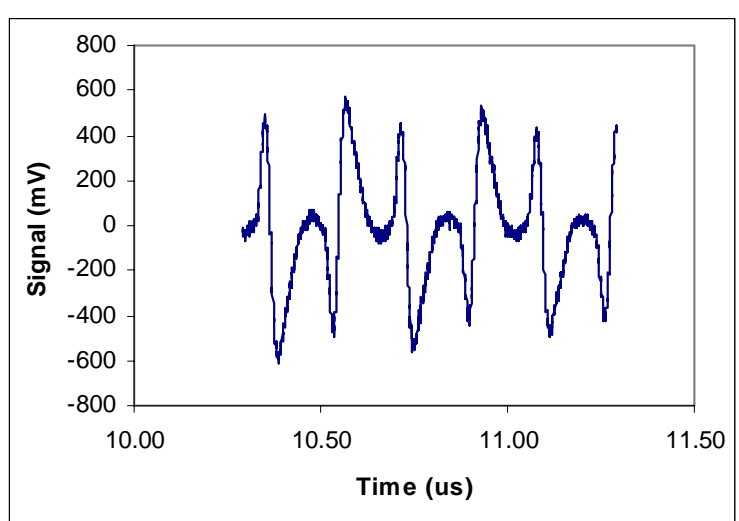

Figure 56. LGS crystal vibration at $850^{\circ} \mathrm{C}$ of the first echo, likely at $\sim 11$ us but obscured by the decaying energy of the initial pulse. Improved coupling to the test object and backing will dramatically reduce the ringing in the signal and make it something more like Figure 48. Probably increased pressure will achieve the needed coupling. In addition, the backing will need to be modified or shaped to minimize confusing echoes. Data is not shown beyond $950^{\circ} \mathrm{C}$ because the leadwires failed at $980^{\circ} \mathrm{C}$, likely due to oxidation.

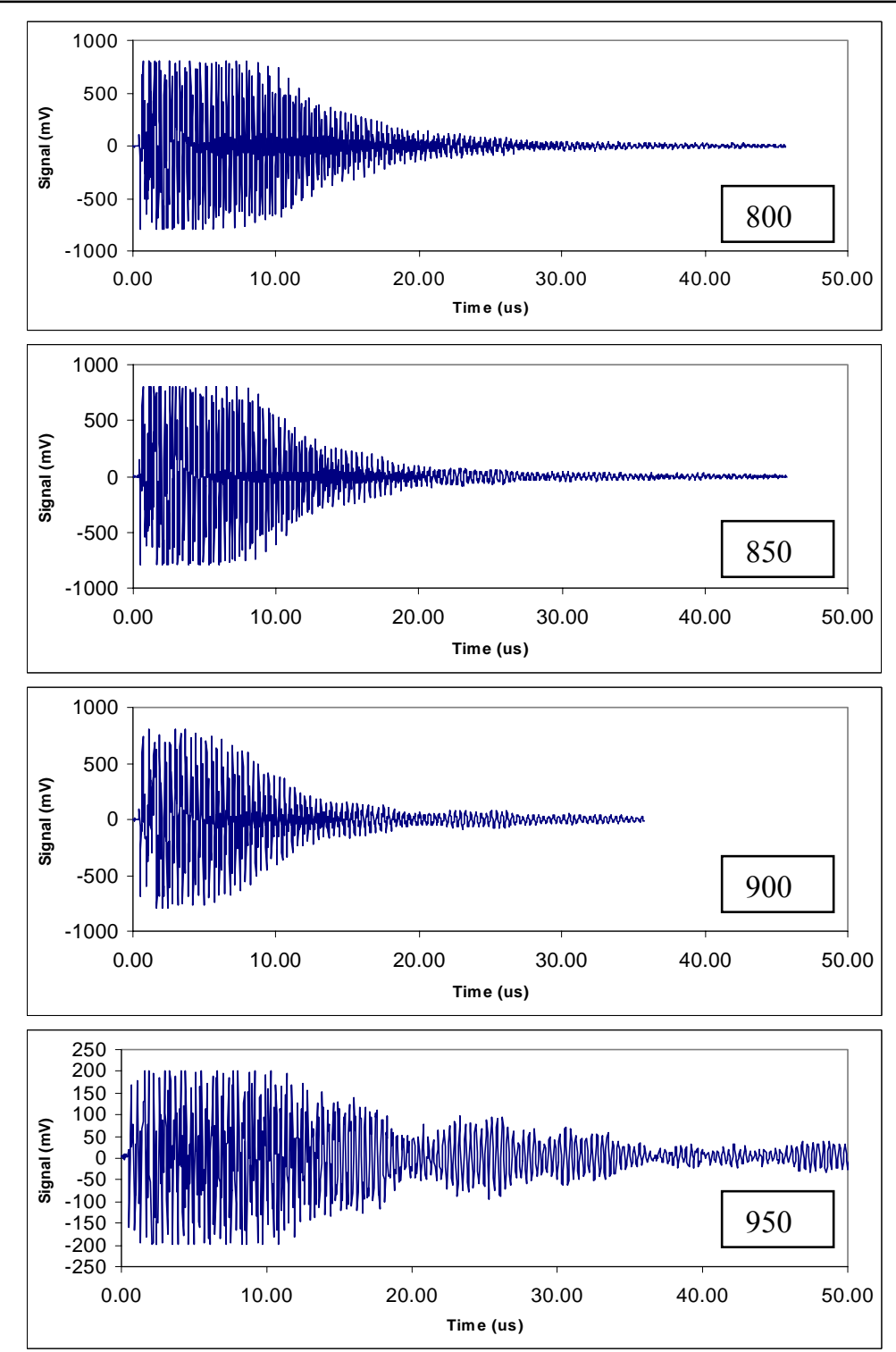

Figure 57. Progression of echo development in titanium block 


\section{SECTION 5 \\ CONCLUSIONS}

Piezoelectric AlN film deposition was successfully transferred from tungsten carbide to other substrate materials, including titanium, conductive bulk AlN, and various forms of SiC. Testing indicated that none of these films were robust enough to withstand the required temperature excursions for a successful sensor. Similarly, pulsed laser deposition of AlN was demonstrated, but is not practical for ultrasonic sensor fabrication. At this time, the AlN films are not recommended for further investigation for general purpose sensors, although there are some niche applications requiring high frequency ultrasound and intermediate temperatures, or radiation hardened sensors, that may be appropriate.

Many of the auxiliary issues for sensor construction were identified and addressed during the program, most notably the issue of high temperature ultrasonic coupling. Coupling using thin metal foils under pressure was very successful, with sound transmission at or above the levels provided by traditional water based couplants at room temperature. Gold leaf was selected as the optimum foil in terms of performance and cost. An alternative to AlN films, single crystal langasite, was identified during the program; preliminary data indicates it holds promise for the targeted sensor applications to above $1000^{\circ} \mathrm{C}$ or higher. Advantages of langasite include oxidation resistance and ready commercial availability in thick (low frequency) sections. Single crystal AlN is becoming commercially available and might be useful in future applications if temperatures exceed the useful range of langasite and oxidation can be excluded.

A demonstration sensor using a langasite crystal, SiAlON backing, and gold leaf couplant was constructed and tested up to $1000^{\circ} \mathrm{C}$ in the laboratory. The langasite performed well in this sensor but ultrasonic coupling or the langasite to the backing material and titanium test block was inadequate, most likely due either to a lack of mechanical pressure, or to effects from the gold paint used to connect leadwires to the active element. Enough coupling was present above $900^{\circ} \mathrm{C}$ to identify a reflected signal from the test block. Future sensors derived from this one have potential for health monitoring in critical, high temperature areas where the tested material is a metal or dense ceramic.

Dissemination of research results to date has included:

- A student senior Honors thesis and associated presentation: "Coupling for High Temperature Ultrasonic Testing", Michael Frede, 2005.

- Technical Presentation: " Piezoelectric Aluminum Nitride Film Transducers for UltraHigh Temperature Ultrasonics ", James Sebastian, Michael Frede, David Stubbs. 25th QNDE, Brunswick, ME, August 2005.

- Poster Presentation: "Ultrasonic Coupling for High Temperature Health Monitoring" James Sebastian, Michael Frede. 25th QNDE, Brunswick, ME, August 2005.

- Technical Presentation: "Recent Advances in Piezoelectric Aluminum Nitride Ultrasonic Transducers for High Temperature Health Monitoring and Inspection" James Sebastian, Michael Frede. ASNT Fall Conference, Columbus, OH, October 2005.

Additional opportunities to present and/or publish results from this research will be pursued. 